\title{
The Criteria for the Evaluation of a Dilute Decontamination Demonstration
}
V. F. FitzPatrick
J. R. Divine
G. R. Hoenes
L. F. Munson
C. J. Card

December 1981

Prepared for the U.S. Department of Energy under Contract DE-AC06-76RLO 1830

Pacific Northwest Laboratory

Operated for the U.S. Department of Energy by Battelle Memorial Institute 
This report was prepared as an account of work sponsored by the United States Government. Neither the United States nor the Department of Energy, nor any of their employees, nor any of their contractors, subcontractors, or their employees, makes any warranty, express or implied, or assumes any legal liability or responsibility for the accuracy, completeness or usefulness of any information, apparatus, product or process disclosed, or represents that its use would not infringe privately owned rights.

The views, opinions and conclusions contained in this report are those of the contractor and do not necessarily represent those of the United States Government or the United States Department of Energy.

\author{
PACIFIC NORTHWEST LABORATORY \\ operated by \\ BATTELLE \\ for the \\ UNITED STATES DEPARTMENT OF ENERGY \\ under Contract DE-AC06-76RLO 1830
}

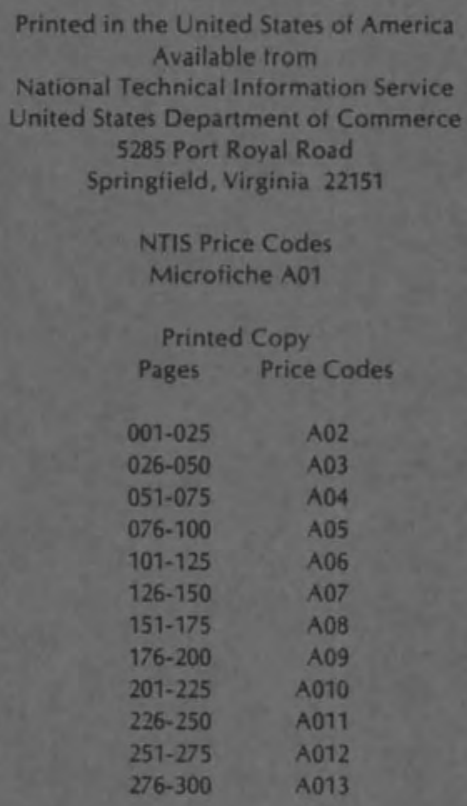


THE CRITERIA FOR THE EVALUATION OF A DILUTE DECONTAMINATION DEMONSTRATION

V. F. FitzPatrick

J. R. Divine

G. R. Hoenes

L. F. Munson

C. J. Card

December 1981

Prepared for the U.S. Department of Energy under Contract DE-AC06-76RLO 1830

Pac ific Northwest Laboratory Richiand, Washington 99352 



\section{CONTENTS}

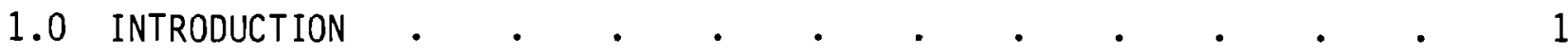

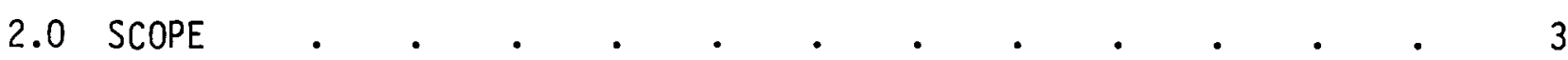

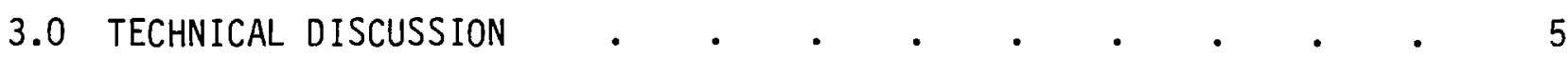

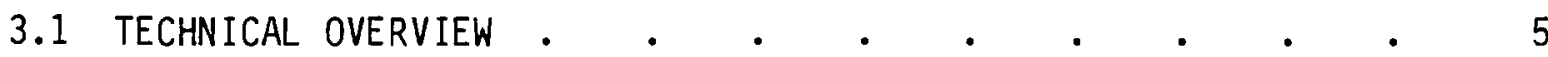

3.1.1 Process Qualification and Status . . . . . . 6

3.1.2 Radiation Level and Measurement . $. \quad . \quad . \quad$. 7

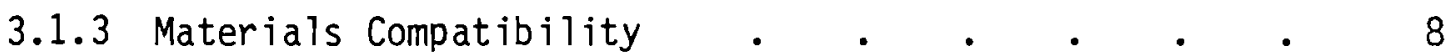

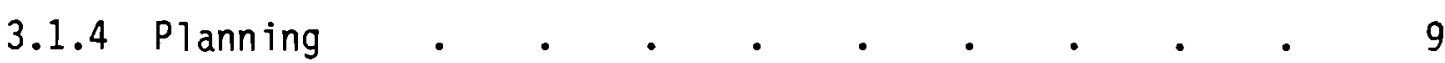

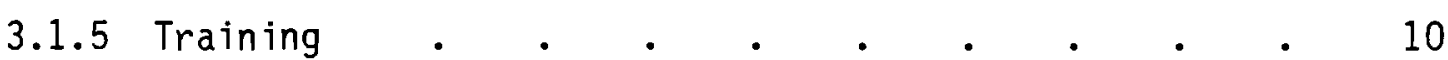

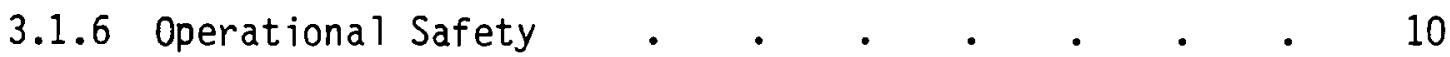

3.2 INTERFACES AND INSTITUTIONAL CONSIDERATIONS $\quad$ - $\quad$ • $\quad$. 12

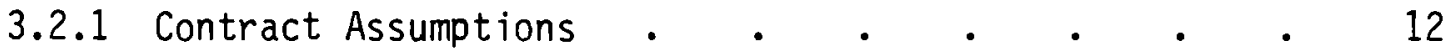

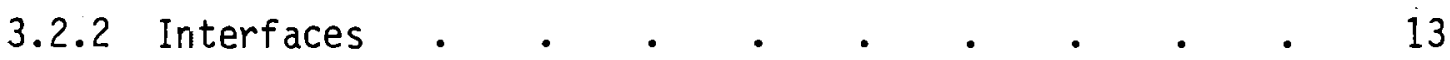

3.2.3 Institutional Considerations $. \quad . \quad . \quad . \quad . \quad 14$

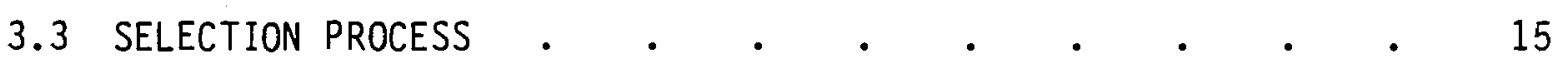

3.3.1 Selection Preparation . . . . . . . . 15

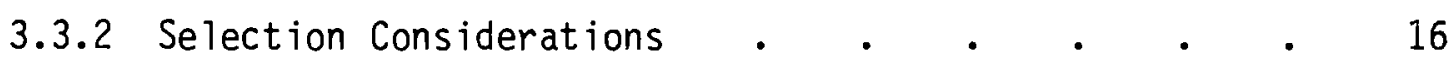

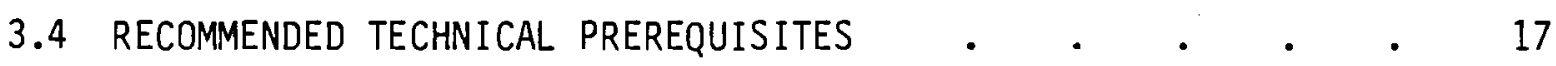

3.4.1 Recommended Reactor Selection Prerequisites . $\quad 17$

3.4.2 Recommended Process Selection Prerequisites . $\quad 22$

3.5 RECOMMENDED TECHNICAL SELECTION CRITERIA \& . • • • $\quad 24$

3.5.1 Reactor Selection Criteria $\quad$. $\quad$. $\quad$. $\quad$. 25

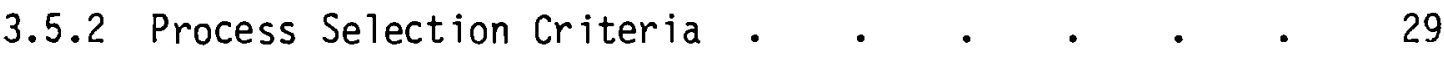




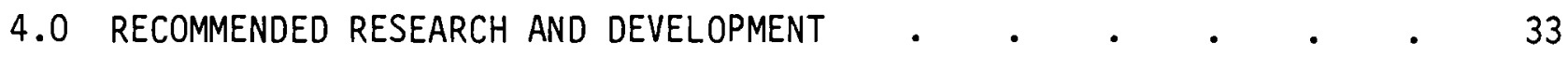

4.1 OVERVIEW OF RESEARCH AND DEVELOPMENT NEEDS . . . . . . 33

4.2 SPECIFIC RECOMMENDATIONS •

APPENDIX A: RECOMMENDED PREREQUISITES AND WEIGHTED CRITERIA

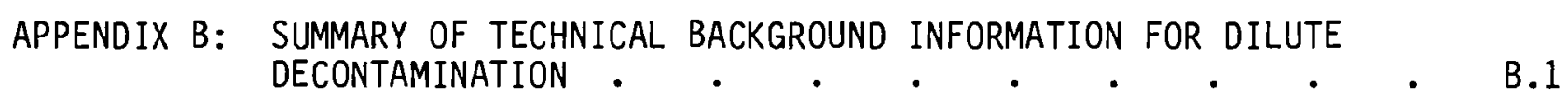




\section{TABLES}

B.1 Structural Materials Used in BWR and PWR Plants . . . . B.2

B.2 Comparison of Operating Conditions for Various Water Reactors - B.3

B.3 Composition of Relevant Alloys . . . . . . . . B.4

B.4 Long-Term Corrosion and Release Rates of the Alloys

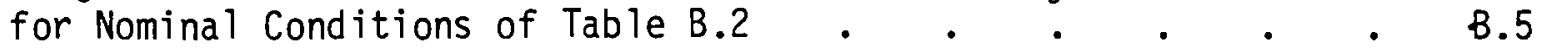

B.5 BWR Core and Ex-Core Radionuclide Activity Densities . . . B.10

B.6 PWR Core Radionuclide Activity Densities . . . . . B.11

B.7 Major Neutron Activation Processes . . . . . . B.12

B.8 Fuel-Crud Structure Observations for Various PWRs and BWRs . . B.13

B.9 Fuel-Crud Thickness Values Reported for Various PWRs and BWRs . B.14

B.10 Crud Source Data . . . . . . . . . . . B.16

B.11 Parent Element Composition of Fuel Crud . . . . . B.16

B.12 Crud Distribution . . . . . . . . . . . B.16

B.13 Radionuclide Composition of Fuel Crud . . . . . . B.17

B.14 All-Location Summary of Radionuclide Inventories of

$\begin{array}{ll}\text { B.15 Reagents, Concentration and App lication Temperatures } & \\ \text { Studied for Dilute Decontamination } & \text { B.22 }\end{array}$

B.16 Experience with Various Dilute Decontamination Techniques . - B.24

B.17 Study Areas and Development Lines for Various Di7ute Decontamination Techniques . . . . . . . B.25 


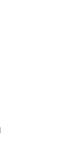




\subsection{INTRODUCTION}

Reactor decontamination is a topic that has been moving to the forefront of current literature, technical seminars and meetings. This movement is prompted by the need to decontaminate reactor systems, subsystems and components and because of the impact of As Low As Reasonably Achievable (ALARA) requirements and operating philosophies on the measurable increase in radiation levels in operating plants. The economic incentives for decontamination are also becoming clearer. In addition, proposed regulations that would substantially lower the level of allowable exposures are causing increased interest in reactor decontamination.

One of the most promising decontamination techniques for achieving substantial dose reductions for operating plant personnel appears to be dilute decontamination. The dilute decontamination method uses mildly aggressive solutions to achieve decontamination factors (DF's) in the range of 2 to 10 , which are sufficient to significantly reduce plant exposures of personnel. Furthermore, the method of application and cleanup of the dilute decontamination chemicals facilitates waste handling, rapid recovery and the return of a reactor to a power-generating mode of operation. Optimistic projections for U.S. reactors, based on the experience at the Canadian Douglas Point Reactor, suggest that a primary system decontamination using the dilute chemical approach can be accomplished in as few as 72 hours.

The main impediment to a widespread application of a dilute decontamination process in the U.S. Nuclear Industry is the lack of proof of the applicability of the process on a power-reactor primary system licensed by the U.S. Nuclear Regulatory Commission (NRC). The first demonstration of the dilute decontamination process will establish the applicability and accompanying economic incentives and requisite protocols. Once the incentives, protocols and precedence are established, many owners of reactors are expected to be interested in using the method, which will result in significant cost and radiation exposure savings for these owners.

One possible method of hastening the first U.S. demonstration of the dilute decontamination process is through a government-industry cost sharing 
program. The U.S. Department of Energy (DOE) requested that the Pacific Northwest Laboratory (PNL) ${ }^{(a)}$ provide the criteria and technical considerations for establishing this joint program. The technical elements are identified, placed in their logical sequence, and a supporting rationale is provided. The document also can serve as the principal technical reference for support of a government procurement action to demonstrate the dilute decontamination process.

The scope of the document is presented in Section 2.0. Section 3.0 is the technical discussion and is divided into six major subsections. Section 4.0 presents recommendations for further research and development of the reactor decontamination process.

Appendix A presents the recommended prerequisites and weighted selection criteria without the supporting rationale. This format allows for easy use of these recommendations by the selection board. Appendix $B$ is a discussion of the technical state-of-the-art for dilute decontamination.

(a) PNL is operated for the DOE by Battelle Memorial Institute. 


\subsection{SCOPE}

This document provides the prerequisite technical information required to evaluate and/or develop a project to demonstrate the dilute chemical decontamination of the primary coolant system of light water reactors. The document is based on available literature, in-house expertise, and current/recent decontamination contracts. This report can serve as a reference document for the formal evaluation of an unsolicited proposal, or it can be the technical basis for preparing a Request for Proposal (RFP).

The document focuses on five key areas:

1. the basis for establishing programmatic prerequisites and the key decision points that are required for proposal evaluation and/or RFP issuance;

2. a technical review of the state-of-the-art to identify the potential impacts of a reactor's primary-system decontamination on typical boiling water reactor (BWR) and pressurized water reactor (PWR) plants;

3. a discussion of the licensing, recertification, fuel warranty, and institutional considerations and processes;

4. a preliminary identification and development of the selection criteria for the reactor and the decontamination process;

5. a preliminary identification of further research and development that might be required, based on the information obtained in items 2, 3, and 4 above. 


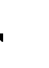

,

. 


\subsection{TECHNICAL DISCUSSION}

The technical discussion of the dilute decontamination demonstration is divided into six subsections as follows:

Section 3.1 -- a technical overview of the state-of-the-art for dilute decontamination processes;

Section 3.2 -- a discussion of the agency interfaces and institutional considerations associated with establishing and conducting the demonstrations;

Section 3.3 -- an overview of the procedure for carrying out the RFP preparation and proposal evaluation;

Section 3.4 -- the recommended technical prerequisites and key assumptions for establishing a contract for conducting the demonstration;

Section 3.5 -- the recommended technical criteria for selecting a reactor and a process for conducting the demonstration;

Section 3.6 -- a preliminary list of the additional research and development recommended prior to a reactor-scale demonstration.

The division into sections facilitates the use of this document as a working reference document for a variety of personnel who may be involved in a selection/evaluation process.

\subsection{TECHNICAL OVERVIEW}

The purpose of the technical overview section is to highlight the key technical considerations that must be addressed in planning and implementing a primary-system decontamination. An underlying philosophy for the approach to a plant decontamination is woven into the overview and these thoughts are also carried forward in Sections 3.4 and 3.5 in the presentation of the prerequisites, selection criteria and supporting rationale. 
The overview is divided into the following areas: process qualification and status, radiation level and measurement, materials compatibility, planning and training, and operations. The material presented in each of the sections is a summary, suitable for evaluating proposals or preparing RFPs and detailed work statements. Technical details such as rates, system inventories and $\mathrm{film}$ characteristics are presented in the technical state-of-the-art summary (Appendix B).

\subsubsection{Process Qualification and Status}

The application of a qualified dilute decontamination process to a reactor's primary system represents a substantial investment in prior development, testing and evaluation. Because "qualified" represents different connotations to different people, the following material is presented to establish the bas is for subsequent discussions. Process qualification is the performance of a prescribed series of testing steps to demonstrate that a candidate process meets the performance criteria (e.g., corrosion and redeposition characteristics, etc.). The testing series consists of five important steps: 1) laboratory beaker studies, 2) bench-top loop testing, 3) large-loop testing, 4) in-reactor loop testing, and 5) reactor demonstration. A process that has been successfully tested by the fifth step can be said to be a "qualified" process. A process that has not been tested by the fifth step is a "candidate" process. While this distinction between candidate and qualified is not necessarily widely accepted, it is the firm conviction of the authors that this distinction be made. The complex process dynamics associated with crud and corrosion product removal and redeposition combined with reagent thermal and radiolytic dissociation and the complex hydrodynamic environment are impossible to simulate in small out-of-reactor loops.

The lack of in-reactor loop-test facilities in the U.S. make adherence to the process qualification recommendations very difficult. However, rather than skipping steps altogther, consideraton should be given to innovative alternatives that provide nearly all of the environmental requirements. For example, constructing a test loop that contains large surfaces of reactor piping and radioactive fuel surfaces containing in-reactor crud deposits can be accomplished using fuel available in a reactor's spent-fuel pool. Spool pieces of 
reasonable length and diameters can be obtained from reactor subsystems. Such a combination, properly engineered, would provide a test environment and should provide a high degree of confidence in test data.

A review of the literature indicates there is potentially only one process that meets the criteria for qualification, the CAN-DECON process. Early Canadian experience at NPD, Gentilly-1 and Douglas Point, combined with the recent U.S. experience at Vermont Yankee, Brunswick and Nine Mile Point would produce a very high level of confidence if there were some assurance that the chemistry was the same throughout the various systems/reactors.

Other potential processes, such as the General Electric (G.E.) dilute process and dilute NS-1, have not been tested to the same degree as the CANDECON process. If an alternate to CAN-DECON were selected, considerable testing would be required.

An important part of the demonstration/qualification program is to perform a second reactor demonstration to assure that the first decontamination did not have an adverse impact on the effectiveness of subsequent decontaminations. There are cases where the high efficiencies achieved on the initial decontamination could not be attained in later decontaminations. It has not been demonstrated whether the chemicals in the initial decontamination have an adverse effect on the film characteristics. Moreover, it is important that a second decontamination be conducted to fully qualify the process and dispel concerns of future reduced efficiency.

Much of the preliminary work could be performed in an in-reactor loop if one were available for test purposes. If appropriate spool pieces were made up, it might be possible to use the fuel pool-loop concept discussed previously.

\subsubsection{Radiation Leve 1 and Measurement}

A good shutdown radiation measurement program is an important precursor to establishing the need for a decontamination and evaluating the effectiveness of the process. Sufficient point source data are required to characterize the system, both in terms of radiation levels and sources and the rate of buildup. 
Very few reactor plants will have this type or quantity of valid data; therefore, it may have to be accumulated as soon as a plant is selected. The number and location of points to be monitored will be an important early point of technical agreement between DOE and the utility. In addition the method of measurement will also be a key technical consideration.

These radiation level data are very important, and the DOE must provide strong input at this stage to ensure sufficient and accurate data are available later in the program. Provisions for post-decontamination surveillance to determine the build-up rate are equally important. These data will be used to establish the degree of decontamination and the rate of buildup or recontamination. These data also will serve as a basis for determining when to perform a second decontamination.

\subsubsection{Materials Compatibility}

Materials compatibility testing is an important part of the qualification process. However, a review of the literature indicates that previous materials compatibility testing is largely unfocused. Even more disturbing there appear to be few if any criteria for determining what are acceptable corrosion rates. The Advisory Committee on Reactor Safety (ACRS) review of the NS-1 data deve1oped for Dresden-1 indicated that this whole area of materials compatibility has been addressed with neither discipline nor rigor.

It is strongly urged that before finalizing any contract, the criteria for acceptable corrosion rates be established and agreed to by all parties. Section 3.5 provides some guidance in this area. Secondly, it is extremely important that any testing program have a specific goäl. This can be accomplished by evaluating the consequences of potential corrosion problem/failures using decision- or fault-tree techniques. The experimental program can then be guided by information that is really required and is likely to be meaningful in the review process. Contracts involving materials compatibility testing should be two-task or two-stage documents. The first task should be to design the testing program using sound analytical techniques. The second task is to conduct the agreed upon test program. 
There should be a visible connection between the materials used in the qualification testing, the coupons and other corrosion monitoring items employed for verification purposes during the actual decontamination, and the materials present in the reactor.

\subsubsection{Planning}

Good planning is an important consideration in any efficient and successful decontamination operation. Poor planning will lead to greater volumes of waste and higher radiation exposures. As an example, data obtained during discussions with Nuclear Steam Supply System (NSSS) vendors revealed that having no advanced planning during a pump decontamination resulted in an exposure of 10 man-rem. By following a written procedure the same work was done with an exposure of 3.7 man-rem. However, by using a written procedure along with training for the staff, the exposure was reduced to 1.3 man-rem.

Planning for a decontamination should begin early. The early planning philosophy is strongly supported by experience from the decontaminations of Shippingport and the Plutonium Recycle Test Reactor (PRTR) in the early 1960s. In both cases, the organizations had undertaken extensive development work in decontamination, yet found that there were deficiencies in the procedures used for decontamination at PRTR in 1962 and at Shippingport in 1964. Planning had not been undertaken as early as was desirable for a rapid response to a need for decontamination or in as great a depth as would have been necessary to avoid operational and maintenance lapses.

The second consideration in supporting a position that planning should start earlier is the current ALARA practice on controliing the exposure to personnel who operate and maintain the reactor systems. If decontamination is a viable alternative to increased radiation levels, then there must be a greater awareness of when this option can be implemented most beneficially, the constraints that are involved in such operations, and the need for coordinating it with other activities associated with the proper operation of the nuclear power system. Contractors involved with the decontamination of the Auxillary Fuel Handling building at Three Mile Island (TMI) used lectures, video tapes and mockups as training aids. They believe that the mockup training was the most 
effective. Total personnel exposure was about 160 man-rem for the period from Apri1 12, 1979, to November 1, 1980, which was about 10\% of the projected exposure. Supervisory personnel feel that training and retraining was a significant factor in achieving the lower exposure levels.

\subsubsection{Training}

The literature indicates and the information supplied by Ontario Hydro and others substantiates the need for very detailed planning and training of operating crews for efficient decontamination. The literature describing the PRTR and Shippingport reactor decontaminations is replete with comments about the importance of having people thoroughly familiar with the various operations that are involved. Ontario Hydro also stressed the need for undertaking complex training programs to fully familiarize personnel with the operations that they are to undertake. Mock runs with water in the systems were performed at PRTR and Shippingport to simulate the addition of the chemicals and their removal so that the staff would be fully familiar with the manipulations that were involved.

Earlier experience with decontamination indicates that there is a great need for the reactor staff to have a thorough understanding of the layout of various items of equipment in the reactor cells. A casual familiarity with the layout will not suffice. All of the key systems that might malfunction or experience difficulty must be we 11 understood. Photographs are needed also so that any maintenance to be undertaken during the course of decontamination can be described fully to the maintenance crew. Experience has shown that exposure is thereby reduced and that repairs are much more expeditiously accomplished. There is also experience indicating that remote TV cameras are valuable when installed in key locations around the reactor system so that any unexpected conditions can be monitored remotely. The crews can be dispatched then for expeditious remedial actions.

\subsubsection{Operationa 1 Safety}

The discussion of operational safety will encompass the effects of chemicals and chemical toxicity, fire prevention, working conditions and organizational considerations. Emphasis will be placed on generalized concepts and on 
providing a "roadmap" to consider the impact of decontamination on safety. Occupational Safety and Health Administration (OSHA) and state requirements will be factored into these types of analyses. A general statement of the considerations involved and their impact if decontamination were used on a reactor system are given so that a full assessment of impacts can be made.

When chemical decontamination of a reactor's primary system is undertaken, sizable quantities of chemicals are involved. For the dilute processes, there may be 1000 to 2000 pounds of chemical reagents used, which means a partial shift in the operation of the nuclear facility from power generation to chemical processing. The operators at nuclear reactor systems would therefore require training in the handing of chemicals. This shift in background needs and experience has often led the owners of nuclear power utilities to choose chemical service organizations to undertake operations involving chemical processing. If that is done, the service personnel have to become familiar with the special conditions, procedures and constraints comonly encountered at nuclear sites. When the safety assessment is made, safety professionals should be involved who are familiar with both types of operations.

The primary fire prevention problem is related to the chemicals and chemical operations that are associated with the decontamination operation. The decontamination materials or their reaction products that are discharged to the radwaste system can be, in some cases, potential explosion and fire hazards. The Manual of Hazardous Chemical Reactions provides information about these hazards.

Another fire prevention consideration is related to the fact that new buildings, special facilities and unusual operating procedures will be required by decontamination operations. The fire safety implications of these changes must be assessed and modifications made to the normal fire prevention and control techniques.

Since decontamination is a very different operation from normal reactor operations, workers must be instructed in the new mode of working. Detailed 
operating procedures must be prepared and approved for the new conditions. A very detailed training program is needed then to teach the approved procedures to the operational crews.

An off-standard operation often results in stress on personnel, if they are required to function in a new manner for prolonged periods of time. Critiques of decontamination operations indicate the need to provide adequate rest to ensure that operations are undertaken in a safe manner.

\subsection{INTERFACES AND INSTITUTIONAL CONSIDERATIONS}

The interfaces and institutional considerations are discussed below in terms of establishing a contract with a utility to conduct a dilute decontamination demonstration. It is assumed that DOE will be providing assistance to the utility on a cost-sharing basis. A series of assumptions and discussions on the contractual relationship are provided to focus the discussion. These assumptions in most cases represent PNL recomendations for the basis for establishing a contract with an utility.

\subsubsection{Contract Assumptions}

The contract for the dilute decontamination demonstration would be between the DOE and the utility that owns and operates the reactor. The vendor who supplies the decontamination chemicals, make-up tanks, and other support equipment would be a subcontractor to the utility. The vendor will also probably supply a significant amount of technical assistance to the utility.

The decontamination must be performed on a reactor where the results of a successful decontamination demonstration would be beneficial to the utility. Indeed, the results of the demonstration should be financially attractive to the utility in terms of reduced operating costs. This financial consideration is key to having the utility take substantial financial responsibility for the decontamination operation and the contingent and residual liabilities. Specifically all costs associated with performance of the actual decontamination operation should be incurred by the utility, i.e., from changes (if required) in the technical specifications of the plant through adding the dilute chemicals, circulation and cleanup. 
The DOE should provide state-of-the-art technical assistance in areas that would be viewed as high risk by the utility. For example, the DOE could take responsibility for disposal of the ion-exchange columns used in the decontamination. The DOE could also provide assistance in planning the operation via their contractor staff. Other items that represent technology transfer to industry can be identified during discussions with the utility.

\subsubsection{Interfaces}

The following are brief descriptions of the interfaces between the DOE and the other contractors and affected agencies.

The Utility--The utility is the principal owner and operator of the plant and the benefactor of the demonstration. The utility in this context refers to the home office or corporate headquarters. The contract will be with the utility. The Plant--The plant is the specific reactor selected for the demonstration. It is expected that DOE's initial interface would be with the utility and the central engineering group of the utility. This interface will shift to the plant staff as the time for decontamination approaches. The plant staff are the performers.

NRC Research--NRC Research represents the agency with the closest interest in accomplishing a successful demonstration. A basis for cooperating and sharing data should be arranged as soon as possible in the program. They represent a "friend in court."

NRC Licensing--The interface of DOE with NRC Licensing is indirect. The main interface with licensing will be through NRC Research, the utility and the plant staff. Early in the program it may be desirable to issue a position paper to NRC Licensing so they are officially apprised of the scope and goals of the program.

Electric Power Research Institute--The EPRI should be very interested in seeing the program culminate in a successful demonstration and may even be willing to fund a portion of the project. If so, the contract should be between EPRI and the utility and have no impact on the DOE-Utility contract. In addition to 
direct funding, EPRI may be able to supply other resources that would increase the potential financial benefits for the utility.

Decontamination Vendor--The relationship with the decontamination vendor and DOE is indirect because the decontamination vendor is a sub-contractor of the utility. The decontamination vendor will be an important source of data both early during the selection and negotiation and later during the actual decontamination postoperation surveillance. (The DOE may choose to participate in the decontamination process qualification. If so, it is recommended that this be covered in the contract with the utility as a lump sum item.)

\subsubsection{Institutional Considerations}

A clear understanding must be reached with the NRC staff to determine who is responsible for the environmental documentation. Consideration should be given to having the DOE or contractor staff write the environmental assessment to insure prompt review and issuance. Assuming that the DOE will be responsible for the disposal of the loaded ion-exchange columns the following approach is recommended.

The DOE should assume ownership of the ion-exchange columns at the completion of the decontamination while the columns are still in place. The DOE would be responsible for unhooking, dewatering, and shipping the columns to the vitrification site. During the shipment the DOE is the owner and a DOE contractor should be the shipper. This combination ensures that the shipment will be governed by the Department of Transportation regulations in Title 49 of the Code of Federal Regulations.

The carrier should be competitively selected by the shipper. The method of shipment will depend on the reactor site selected for the demonstration.

The utility will want indemnification for all work associated with the ion-exchange columns that is performed by the DOE or their contractor on the reactor site. The arrangement for meeting this request should be fairly straightforward, patterned after the acquisition and removal of the steam generator from the Surry site. The indemnifications associated with transport and disposal are slightly more complicated. The contract between the DOE and their 
contractor must be changed to allow the DOE Price Anderson indemnification to be prime. This was accomplished without significant perturbation for shipping the Surry Steam Generator.

\subsection{SELECTION PROCESS}

A selection board should be used for either the RFP or unsolicited proposal method of choosing a utility for the dilute decontamination demonstration. The board process provides a wide range of critical skills during the selection and evaluation process. It also provides a nucleus of key people to draw on during contract negotiations, if such assistance is required.

This document is intended to be used as a working technical manual for the board members during the selection, evaluation and clarification processes. Rather than attempt to duplicate existing procedures, this section will provide a compendium of insights and considerations that the authors have acquired by serving on selection boards.

\subsubsection{Selection Preparation}

The criteria used in the selection process should be the same for both the RFP or the unsolicited proposal approach. The absence of information represents a deficiency that must be clarified.

The prerequisites and weighted criteria presented in Sections 3.4 and 3.5 of this document should be adopted in total. This adoption will provide the board with a referable evaluation basis, including supporting rationale.

The technical prerequisities in this section are analogous to the administrative prerequisites in the Federal Procurement Regulations. The proposal must meet the prerequisites, or it will be considered unresponsive and cannot be evaluated further.

The board should determine, using the weighted criteria in Section 3.5, the content and points for a minimum technically acceptable proposal. The above data and decisions can be used to prepare and approve Commerce Business Daily announcements and RFP work statements. 
In addition to the appointed board members (who vote), the board may choose to obtain the services of key personnel (as nonvoting members) who are going to be involved in the execution of the program.

\subsubsection{Selection Considerations}

The task assigned to the utility is complex and challenging. An experienced management team will be required to accomplish the objectives. The management team's attitude toward cost and schedule will be very important. A description of the experience of the team, individually and as a team, should be obtained and evaluated.

The utility will probably rely on outside assistance, either from their architect engineer (AE) or job shops. The number, qualifications and responsibility of these people should be evaluated carefully.

The definition and division of responsibilities should be stated precisely, if not in the proposal, then in clarifying questions. Questions of clarification should always be written and agreed to by the selection board. Answers to these questions should be obtained verbally by conference call and in writing by return telecopy or TWX. Written answers should be provided within 24 hours, if possible.

Meetings between the candidates and the selection board are helpful in resolving outstanding issues and questions. The content and overall agenda for the meeting should be established by the selection board. Specific questions should be provided.

Key plant personnel who represent the corporate and operations staff must be involved at this stage. It is very desirable to have a blend of input from those who make policies through operations.

The utility is responsible for selecting the decontamination process. The choice of a commercial and potentially proprietary process may not be what the selection board considers optimum. However, the board must determine if the process can be accepted by NRC in a time frame that is compatible with the demonstration schedule. 


\subsection{RECOMMENDED TECHNICAL PREREQUISITES}

This section gives the recommended technical prerequisites for both the selection of a reactor plant (Section 3.4.1) and the dilute decontamination process (Section 3.4.2). These are prerequisites in the contractual/procurement sense of the word; that is, they must be met fully or the proposal is nonresponsive. The supporting rationale for the prerequisites is also provided. These supporting data are presented with the intent of providing the selection board with a justification for accepting the prerequisite and a method of determining if the prerequisites have been met.

\subsubsection{Recommended Reactor Selection Prerequisites}

Nine recommended reactor selection prerequisites are identified. These prerequisites and their rationale are presented as follows:

1. The plant used for the demonstration will be a currently operating licensed power reactor located in the U.S.

The objective of the program is to conduct a demonstration that will establish enough protocols and precedence so that the next application can proceed with relative ease. The owners of power reactors licensed by the NRC are required to establish meaningful protocols and precedence for the nuclear power industry. The reactor must be currently operating to have corrosion product films that are likely to be representative of a large number of plants.

The application of a dilute decontamination process to a unique or nonoperational reactor will not provide a solid basis for technology transfer, which causes the first-time regulatory review process to be repeated in toto when applied elsewhere.

2. The plant shall be capable of operating after the decontamination and the utility management shall be willing to operate the plant several years after the decontamination.

Information on recontamination rate and long-term effects on fuel performance is required to provide the maximum incentive for wide- 
spread application of the dilute decontamination process and therefore the dose reduction benefits. Without these data, industry acceptance is unlikely. Therefore, an approach where the decontamination is a precursor to either decommissioning or an extended layup is unacceptable from a programatic standpoint.

Continued and extended operation after the decontamination is required to obtain data on actual personnel dose reductions. Also data on film characteristics and performance information on systems and components cannot be obtained without substantial postdecontamination operation.

3. The plant and utility management must be committed to performing the decontamination demonstration in a timely fashion.

The rapid and widespread acceptance of the dilute decontamination process requires that the precedents be established within a reasonable time frame. The penetration of a new technology into the market place typically follows an "S" curve. Factors that skew the initial position of the curve by lengthening the penetration can significantly delay and/or reduce overall acceptance. Therefore, a dedicated management team is needed who will aggressively (and successfully) perform the demonstration within a reasonable time, such as two years after establishing the contract.

4. The plant and utility management shall be willing to perform a second decontamination either at some specified future date or based on demand by radiation level buildup.

The philosophy of the dilute decontamination process is based on the ability to perform additional decontamination on an as-required and/or periodic basis. This suitablility for repeated use should be demonstrated to prove that the process does not condition the surfaces so that the effectiveness and efficiency of future decontamination is impaired.

The second decontamination will provide a better means of assessing occupational dose savings and of demonstrating the costs/benefits of 
demonstrated, periodic dilute decontamination. Demonstrated assurance that periodic applications do not impair future operations will improve the acceptance and application of dilute decontamination by industry and licensing agencies.

5. There shall be free and open cost information associated with the decontamination operation so that a complete and realistic cost benefit analysis can be performed.

Cost data currently available are of marginal value for actually performing a cost benefit analys is on whether or not to perform a dilute decontamination. The dollar value of a man-rem of exposure has not been established for occupational exposure. However, the technology transfer to be achieved by the demonstration demands complete dissemination of relevant information. Considering the difference in accounting systems from one utility to another, a complete record of manhours expended (by job classification) may be the most useful form of cost information.

6. There shall be no significant history of fuel failures, steam generator tube failures/plugging or large-diameter-pipe cracking. A primary system containing fuel-element rupture debris presents an entirely different decontamination problem from one that has only a film-transport radiation problem. At th is time there is no known dilute decontamination method capable of dissolving fuel debris. Should such a method be developed, the following considerations would preclude its use as a demonstration of dilute decontamination.

a) Radioactive gases contained in the fuel would be released during dissolution and increases the problem of venting the systems.

b) Fuel debris would mask the radiation caused by film transport so that process evaluation would be difficult.

c) Dead-leg flushing hazards would be increased due to the potential of flushing undissolved fuel debr is with attendant highradiation and physical-control problems. 
d) Waste handling difficulties would increase greatly if plutonium were in the waste streams.

e) Release of fuel element debris in the primary system could materially change the film characteristics and would invalidate any results as being typical of a power reactor.

f) It would be most difficult to prove that the dilute decontamination had not adversely affected the fuel elements if there already was fuel debris in the system.

There are two principle concerns when conducting a decontamination demonstration in a reactor system with known component integrity problems. First, the replacement of a failing/failed major component demands extended and detailed negotiation between owner and supplier. Nonstandard operations such as a system decontamination could seriously hinder any negotiation/fact-finding process. Actions that could lead to any actual or implied liability to the program or DOE represent unnecessary and unwarranted risks.

Secondly, there is no clear way of sorting out any effects that are initially difficult to explain after the decontamination. There will be a tendency to assign the decontamination process the responsibility for new and/or accelerated corrosion problems. Th is tendency was observed in several cases after the first decontamination of PRTR. Potential problems can be avoided if a system with a known history of problems is not used. This is especially true in PWRs where a significant number of questions on the effect of the solution on steam generator tube cracks and crack propagation would be raised.

If the decontamination chemicals escape from the primary system into the secondary system, a variety of undesirable events might occur. For example, there might be an unexpected release of radionuclides into the secondary system. This release, in turn, would complicate waste handling problems. It is very likely that the decontamination chemicals might not be compatible with secondary system materials. This incompatibility might produce unexpected corrosion problems. 
Another possibility is that the decontamination chemicals might not be compatible with boiler-control chemicals.

7. The plant and utility management shall comit to an expanded shutdown radiation measurement program that will be performed before and after the decontamination.

Evaluation of the decontamination process requires a series of precise measurements to characterize the system before and after the decontamination. These measurements must be point readings that can be repeated each time the reactor is shut down. This repetition is required to determine the initial effectiveness of the decontamination and the recontamination buildup as a function of operating time. Area measurements are neither repeatable nor effective in analyzing the recontamination.

8. The decontamination shall be performed with the fuel in place. The basic philosophy of the dilute decontamination is to apply a process that can be performed quickly, effectively and as frequently as required. A quick performance is one that could be done within 72 hours and that would prevent the decontamination from being on the outage critical path for an extended period. At shutdown costs of $\$ 500,000 /$ day, any significant length of time on the critical path would significantly impact the economics of the decontamination operation. If a complete defueling and refueling were charged to a dilute decontamination, the operation would appear totally uneconomical because of replacement power costs.

The effectiveness refers to achieving a reasonable decontamination factor in the out-of-core system and to retarding the recontamination rate. Estimates of activiated corrosion product sources vary considerably; however, more than half of the inventory is deposited in-reactor on the fuel surfaces. If a significant portion of this potential source can be removed, the recontamination rate should be lower. The data from Douglas Point tend to validate this point. 
9. All warranties for fuel, equipment and systems shall be the responsibility of the utility, and no contingent or residual liability shall be assigned to the DOE or their contractors.

Selection of the process, controlling the interface with the process vendor, and changes and adherence to the plant technical specification are the responsibility of the utility. Judgments on the compatibility of materials are also the utilities' responsibility. These responsibilities, when combined with the obvious fact that the utility is the contracted party with the plant vendors, make it impossible for any other party to assume the main responsibility for any liabilities to the primary system during a dilute decontamination. This position will help to establish a utility-vendor precedent for including decontamination considerations in equipment and fuel warranties.

There may be some questions of seeking indemnifications from the DOE; however, DOE indemnifications would only be approriate where their contractors perform work on the site.

\subsubsection{Recommended Process Selection Prerequisites}

Six recommended process selection prerequisites and the ir rationale were identified. These prequisites and the supporting rationale are presented as follows:

1. A dilute decontamination solution contains less than one percent chemicals by weight.

Usually dilute decontamination is considered to be in the $1000 \mathrm{ppm}$ (0.1\%) range; however, decontamination factors tend to be low (2-10) in this range and the possibility of using a more concentrated solution should not be precluded. Increasing concentrations would increase the waste handling problems to the point that dilute decontamination may not be cost effective. A maximum chemical concentration of $1.0 \%$ seems to give sufficient latitude in process selection, commensurate with current experience. 
2. The demonstrated corrosion characteristics of the solution will allow completion of the decontamination with a corrosion loss of less than $10 \%$ of the allowance for the fuel, materials and systems that are in contact with the solution.

Dilute decontamination is a process that theoretically can be applied several times during the life of the reactor plant. Observing typical radiation level build-up data, a plant could be decontaminated with the dilute process every four to five years or nominally five times over the effective plant life. Therefore, to be effective, the corrosion allowance for the dilute process must be compatible with up to five applications. The plant corrosion must make allowance for other events such as steady state corrosion etc.; therefore, no more than $50 \%$ of the plant corrosion allowance should be set aside for the dilute process--hence $10 \%$ per application.

3. The dilute decontamination solution will be no more likely to produce catastrophic effects than normal plant operating conditions.

The reaction of the dilute decontamination solution with all materials where a corrosion-induced failure could have a serious impact on either the public health and safety or plant operations can not be tolerated. This includes normal decontamination operating conditions as we 11 as upset conditions, such as a pump failure that could lead to stagnation of the decontamination solution, and residual effects during power operation.

4. The decontamination solution will be suitable for the entire primary system.

The decontamination solution will have to have demonstrated corrosion compatibility with all major types of materials found in a reactor's primary system, including galvanic couples. This implies a much broader spectrum of materials than is covered in item three above. Internal materials, such as valve-seat facing, etc., are included in this category. Based on experience at PRTR, the list could easily include 100 to 200 different materials or heat treatments. 
5. The process will be capable of being completed in 72 hours.

This prerequisite is aimed at the economic aspects of a dilute decontamination, specifically at minimizing chargable outage time. This requires that the solution not adsorb to any significant extent on system surfaces and that solution trapped in crevices be easily thermally degradable into harmless products.

6. The company supplying the decontamination chemicals must be willing to disclose the entire solution formulation.

Since the objective of dilute decontamination is not to "reinvent the wheel" but to demonstrate feasibility of the concept in a U.S. industrial reactor, commercial processes must be considered. If this program is to materialize in a timely fashion, research and development efforts must be minimized. This can be done by using proven commercial processes.

The chemical constituents of the material injected into the primary system on a commercial process may be proprietary; however, the vendors must be willing to divulge this information on a very limited need-to-know basis. This is a very critical point and one that must be resolved with the vendor at the earliest possible time by using nondisclosure agreements with the appropriate parties. Experience with chemical vendors has shown that the formulation of proprietary solutions is not necessarily fixed but sometimes varies with the batch, and in some cases "a pinch of fluoride has been added for bite." Risks of such manipulation must be eliminated.

\subsection{RECOMMENDED TECHNICAL SELECTION CRITERIA}

This section gives the recommended technical selection criteria for both the reactor and the process. This section should be used to review the proposals that meet all of the prerequisites set forth in Section 3.4.

The criteria and the supporting rationale are provided. In addition, weighting factors have been suggested for each of the criteria. The number of points reflects the authors' opinions of the relative importance of each 
criteria. The assignment of points is subjective; however, it provides a visible and traceable method for evaluating proposals. These criteria and their assigned weighting factors can also be used in preparation of a RFP.

The criteria can be used in evaluating any proposal, either unsolicited or in response to a RFP. If important criteria are not addressed, this represents a basis for issuing questions for clarification.

A minimum score for an acceptable proposal should be established before reviewing any proposals.

\subsubsection{Weighted Reactor Selection Criteria}

Twelve recommended technical reactor selection criteria and their rationale are listed as follows:

1. The reactor sha 11 have been operating for a reasonable and representative time (less than 5 years is 0 points).

(15 points)

It is important that the film surfaces in the reactor be representative and that decontamination is a necessary and desirable activity. The expected cooperation from the utility and affected agencies would be much greater if there was a real demonstrated need for decontamination to meet ALARA comitments and to permit maintenance and/or inspection in a cost efficient way. It is also very desirable to have enough operating time to ensure that inherent operational problems in the plant have been documented. This documentation should be reviewed and evaluated after the decontamination.

2. The utility must have an acceptable Health Physics Program--data from the NRC-PNL Health Physics Appraisal Program will provide the basis for judgment. The utility must also show a willingness to correct deficiencies.

(25 points)

The assessment of acceptability will be made on the basis of data collected from the NRC-PNL Health Physics Appraisal Program. Where deficiencies have been identified, the utility/plant staff shall submit a plan for corrective action. The established plan/program a! so provides a basis for documentary modification that must be made during the decontamination. 
3. The plant will have an adequate shutdown radiation measurement program and history.

(30 points)

An adequate shutdown radiation measurement program will contain the elements: 1) documentation of radiation levels at previous outages, 2) documentation of radiation levels before the decontamination, 3) a plan for obtaining measurements during and after the decontamination, 4) calibration techniques (for measurements), 5) consideration of contact dose rates versus area dose rates, 6) correlation of dose rates to high worker-occupancy areas, 7) a method of assessing the effect of decontamination on dose rates, and 8) a measurement accounting system.

4. The utility will propose an experienced and dedicated team, familiar with the plant. The evaluation will also include any proposed contract personnel or AE staff.

(25 points)

The team must have a clear line of authority for controlling action from planning through implementation. There will be sufficient documentation to show the individual experience as well as team experience. Consultants, contract personnel and AE staff will be identified.

5. The plant staff will have prior decontamination experience. (15 points)

This refers specifically to solution decontamination of systems, subsystems and/or major components. No points are given for small-tool decontamination experience. Prior experience of personnel, such as with the nuclear navy, would be valuable, and points should be awarded for this experience. A decontamination officer whose responsibility is to stay abreast of the technology and direct all decontamination work on site would also be valuable. These factors should give the DOE confidence that the utility staff has the competence to plan and execute a dilute decontamination.

6. The utility will submit a brief (not more than six pages) Operational Plan. 
This document represents the basis for knowing whether the utility fully understands and is prepared to perform what must be done to execute a successful dilute decontamination of a reactor primary system. The plan will address industrial health and safety, nuclear safety, operation procedures, ALARA considerations, safety analys is, waste handling, vendor interfaces, etc.

7. The utility sha11 demonstrate a detailed knowledge of the wettedconstruction materials in the primary loop.

(35 points)

This is an extremely important area because a thorough knowledge of the wetted portions of the primary system is the first step in actually and realistically defining the degree of difficulty, the deadleg flushing requirements, etc. On the original submission this is one of the most subjective areas. During interviews the board will need a series of questions to determine the utility owners' actual knowledge of the system.

8. The utility shall submit a plan for determinining the overal1 decontamination factor. (If included in the operation plan it should be an easily identifiable section).

(15 points)

It is necessary to develop an adequate means of measuring whether the decontamination-factor data are relevant and realistic. A poor selection of the points of radiation measurement could bias the decontamination factor. The method of measurement and of instrument calibration will be identified. Plans for mitigating the potential effect of background radiation will be presented. The number of points, their location and the rationale for selecting the points will be provided.

9. The utility shall present a discussion of the proposed staff training program.

(10 points)

A staff training program is a key element to conducting a successful decontamination. Training at TMI for the Auxillary Fuel Handling Building was a ratio of about 10 hours training per 1 hour of detailed work. The training program should identify the following 
elements: radiation worker training, plant system familiarity, mockup, emergency response, industrial hygiene and safety problems, and specific procedure use and provisions for debriefing.

10. The utility shall identify the major changes required to implement a dilute decontamination and shall provide an assessment of the degree of difficulty to make these changes.

(15 points)

From a project-cost standpoint, the selection of a demonstration reactor with a system that is easily modified to accept the necessary auxiliary equipment would be advantageous. This should not be an overriding feature since selection of a typical reactor is more important.

The ease of modification takes into consideration such items as the radiation levels, location for permanent makeup and waste tanks, space for ion-exchange systems, dead-leg section availability, etc., but in the final analysis, inspection of the reactor will readily indicate problem areas and their magnitude.

11. The utility shall provide an overall cost estimate for the first dilute decontamination and cost sharing proposal.

(30 points for cost realism)

This is an area of technical judgment that must be dealt with along with other criteria. It must be clearly understood that the critical item is not the lowest cost--but the most realistic cost based on the proposed scope and schedule. Many clarification questions can be anticipated.

12. The utility shall provide an overall schedule to support the cost estimate with key milestones/decision points identified. (15 points)

The key items here are: 1) a realistic schedule based on the proposed scope and resources available, 2) an aggressiveness demonstrated in completing the decontamination in a timely fashion, and 3 ) the practical experience of key personnel. 


\subsubsection{Process Selection Criteria}

The eight recommended technical Process Selection Criteria, with the recommended weighting factors and their rationale, are listed as follows:

1. If the decontamination solution is required to perform outside of the tested range, there shall be sufficient data available to make judicious extrapolations.

(25 points)

The rate of corrosion certainly has to be established; however, the permissible corrosion penetration will not be the same for all components within the system. Permissible limits may also have to be established after all of the components and materials are identified as all of the materials may not have been evaluated in the tested ranges. Probably the most critical components will be those in the fuel assembly.

Certain types of corrosion should not be permitted in acceptable dilute decontamination process. This should include but not necessarily be limited to: pitting, residual crevice corrosion, chloride stress-corrosion cracking, and caustic embrittlement.

In establishing corrosion rates the basic consideration must be that the utility will have to assure NRC that the systems and components are not damaged by the dilute decontamination.

In some areas it may be necessary to extrapolate to higher concentrations, temperatures or flows. The extrapolation should be reasonable and based on standard chemical engineering practice by experienced personne 1.

2. The target decontamination factor is 4-6. (25 points) Ideally the selected dilute decontamination chemicals should provide maximum decontamination factors with minimum impact on the primary system and associated components and systems. Such ideals are seldom if ever attained; therefore, realistic trade offs will be required. A decontamination factor goal should be established for the process, with the realization that once the decontamination is started the results must be accepted. A minimum overall goal of 5 is recommended. 
A major consideration in the selection of a process has to be how the decontamination solution reacts with the primary system. Ideally, the process should not produce undesirable decomposition products either gas, liquid, or solids since they may perturb the decontamination and waste handling operations. The process also should not produce sludge since the solids tend to settle out in areas of the primary system where there is low flow such as crevices. This condition generally will not allow the removal of film material and leads to low decontamination factors.

Some of the decontamination solutions have the ability to remove film from the system but do not appear to be able to retain the material in solution for a variety of reasons. Redeposition of dissolved materials in a uniform manner will result in lower radiation readings in some areas and increased readings in others. In many instances this creates problems rather than corrects them. The redeposition can frequently be attributed to holding the decontamination solution in the primary system for too long. The processes that commonly occur are the radioloytic breakdown of the decontaminant and production of insoluble corrosion products that carry down radioactivity. In dilute decontamination it becomes very important that these phenomena do not occur. The "halflife" of the decontaminant also provides a valuable input to the criteria for determining when the decontamination is complete.

3. The utility shall propose any in-reactor corrosion verification testing that may be required during the decontamination.

(15 points)

Unique problems occur in specific areas during system decontamination that are of special concern during dilute decontamination. In this respect information must be available or readily obtainable regarding corrosion around stubs, valves and gaskets. Some of the corrosion in this area is due in part to galvanic action or residual crevice corrosion. The residual crevice corrosion may be due to thermal and radiolytic decomposition products or the presence of chemicals in 
crevices but not in the bulk solution. If these areas have not been sufficiently investigated, additional program time may be lost due to research and development needs.

4. The vendor shall specify the waste volume and form.

(40 points)

A consideration that could easily be overlooked in the selection of the process is how easily the chemicals can be removed from the primary fluid. This consideration has two parts: First the ionexchange resin-load capacity for the given chemical has an impact on the costs. For example, a chemical that requires a cubic foot of resin for 3500 grains would require twice the resin that a chemical that required a cubic foot of resin for 7000 grains of removal capacity--this reflects in equipment size, resin costs and waste disposal costs. Secondly, the degree of cleanliness of effluent and the rapidity with which an acceptable level is reached can severely impact the dilute decontamination effort by creating an unnecessarily long outage.

NOTE: It is assumed for a dilute decontamination that ion-exchange cleanup is required; therefore flushing, etc. does not enter into waste volume considerations.

5. The vendor shall submit a plan for managing the chemical and industrial safety and toxicity problems.

(15 points)

The chemical to be used in the decontamination should be reviewed regarding stability, toxicity and purity. The stability may impact drastically on shipping and disposal problems; the toxicity on the design for chemical handling and control systems and potential industrial hygiene problems. The purity problem is associated with special corrosion problems such as chloride stress corrosion.

6. The temperature of the decontamination operation shall be minimized. (Proposed operating temperatures above $160^{\circ} \mathrm{C}$ will receive 0 points). (25 points) 
Heat can be added by the circulating pumps, from external heaters and reversing the steam generator; however, the temperature should be controlled as low as practical.

7. The vendor shall supply a proposed operating plan/approach, including discussion of the interface with the reactor's operating crew.

(20 points)

The purpose of this plan is to clearly identify the responsibilities on the vendor/chemical-supplies side of the interface. This will most likely include solution make-up/injection and operation of the solution refurbishing and purification equipment.

8. The decontamination solution shall exhibit a wide range of stability, e.g., the temperature control requirements will be $\pm 10^{\circ} \mathrm{C}$ minimum; the solution can be left in the system, stagnant, for up to a week with no adverse effects. (40 points)

It is important to the selection of the process that the latitude allowable in each parameter be fully understood. It is also important that the process system can be maintained with in acceptable limits. For example, How closely must the temperature be controlled? What happens if the parameters are exceeded? Can the system(s) be controlled to acceptable limits? The same thinking must be applied to all other parameters such as $\mathrm{pH}$, concentration, pressure, time of contact, etc.

The one-week period allows a large margin of safety in case of equipment failures. Temperature effects on the decontamination factor during this period should be determined. 


\subsection{RECOMMENDED RESEARCH AND DEVELOPMENT}

The discussion on recommended research and development is divided into two sections, an overview and recommendations for the demonstration project.

\subsection{OVERVIEW OF RESEARCH AND DEVELOPMENT NEEDS}

Dilute reagent decontamination of PWR and BWR plants is under continuing study because of its attractiveness from the standpoints of:

- limited shutdown times

- decreased general plant exposure rates

- relatively small reagent and set-up costs

- generally low corrosion rates.

In particular, the effects of oxygen concentration and $\mathrm{pH}$ have been examined extensively to determine their effects on materials of construction, crud layers, and overall decontamination factors. These are, however, significant areas of concern that merit increased study to assure that the continued safe operation of a facility will not be jeopardized.

One of the common concerns for PWRs and BWRs is the performance of crud layers in various reagent systems. This is a complicated problem since the chemistry and structure of these films is complex and often varies significantly with location within a given plant and from plant to plant of a given type. In-core crud layers appear most often to be cation-substituted ferrites such as $\mathrm{NiFe}_{2} \mathrm{O}_{4}$. Ex-core cruds are generally composed of spinels and mixed oxides. There are continuing research needs for:

- qualification of various reagents for fuel-crud removal;

- definition of conditions that cause particulate releases from crud layers;

- identification of the effects of temperature, heat flux, radiation fields and hydrodynamics on the structure and composition of crud layers and on crud transport;

- receptor-surface charge adjustment to minimize crud deposition; 
- ion additions to alter the electrochemical condition of particulates to prevent their precipitation during decontamination.

Overall the observations of the distribution of in-core crud deposits do not indicate a strong influence of heat flux or radiation on crud deposition. However, this should be verified.

Research needs related directly to the performance of decontamination agents include:

- laboratory and pilot-scale characterization of the corrosiveness of reagents on specific systems;

- study of the stability of reagents under temperature, heat flux and radiolys is effects to determine whether decontamination should occur immediately after shutdown or be delayed several days to allow natural decay to reduce short-lived, highly active species;

- identification of the optimum ion-exchange resin from the volume reduction of various decontamination agents;

- evaluation of the variation of corrosion rates for different facilities of the same type with the same reagent;

- characterization of the impacts of borated coolant on decontamination in PWR systems;

- development of more efficient dewatering techniques for ion-exchange resins;

- development of techniques of inspecting fuel rods in-reactor;

- development of post-decontamination passivation techniques;

- development of nondestructive testing methods to detect cracks in the primary piping (for the entire prinary system);

- study of the effects of detergents, surfactants, complexing agents and other chemical additives on solidification of decontamination solutions; 
- study of the effects of detergents, surfactants, and complexing agents on the efficiency of resins;

- study of the compatibility of resins with solidifying agents;

- development of improved solidification methods for dry (or dewatered) resin;

- development of method of regenerating resin using a low-volume liquid that could be evaporated and solidified with cement (i.e., have a low-volume liquid waste rather than resin as waste).

Potential studies for post-decontamination (both between the first and second and after the second are:

- develop a method of economic analysis to show the cost/benefit of dilute (or other) decontamination techniques over the entire lifetime of the plant (from facility design through decomissioning);

- study design and layout improvements for reactor plants to facilitate decontamination;

- develop criteria for industry for timing the need for doing a decontamination--probably using shutdown radiation measurements;

- study the effect of decontamination on reducing man-rem in the reactors; i.e., assess the overall benefit of decontamination as a means of maintaining radiation doses ALARA;

- study the effect that a decontamination has on the routine radioactive effluents from a reactor;

- study the effect that a program of routine periodic decontaminations has at the time of decommissioning;

- study the impacts associated with long-term storage or disposal of wastes containing chelating agents;

- study the buildup of contamination following a decontamination. 


\subsection{RECOMMENDATIONS}

If the demonstration project is to fulfill the prescribed mission, a commercial process must be used. Therefore, many of the studies presented above that are precursors to process selection and qualification would be eliminated from consideration. DOE-funded research and development should be focused on the areas of waste treatment and disposal, radiation buildup, economics and post-decontamination effluent effects.

A comittee of interested and affected agencies should be formed to help ensure that the maximum amount of useful data can be obtained from the demonstration project. Cormittee membership should include the DOE, the NRC, and the EPRI, plus selected consultant and/or contractor personnel. The committee could be formed after the negotiations for the demonstration project are complete; however, consideration should be given to using committee input to assist in formulating positions on some of the technical details to be negotiated. At first glance this may seem to avoid specific recommendations; however, specific proposals can be extracted from Section 4.1 , based on the final negotiations for the demonstration project.

The cormittee should exist long enough to provide input to the project negotiations, to identify key areas where specific research and development proposals would be of significant benefit, to formulate a strategic approach for obtaining that data, and to make recommendations as to which agency should fund which activities. The costs for such a comittee should be small if key program people in the agencies are the constituency. This will also facilitate implementation of the recommendations. 
APPENDIX A

RECOMMENDED PREREQUISITES AND WEIGHTED CRITERIA

FOR THE SELECTION PROCESS 
APPENDIX A

\section{RECOMMENDED PREREQUISITES AND WEIGHTED CRITERIA \\ FOR THE SELECTION PROCESS}

\section{A.1 RECOMMENDED REACTOR SELECTION PREREQUISITES}

1. The plant used for the demonstration will be a currently operating licensed power reactor located in the USA.

2. The plant shall be capable of operations after the decontamination and the utility management shall be willing to operate the plant several years after the decontamination.

3. The plant and utility management must be committed to performing the decontamination demonstration in a timely fashion.

4. The plant and utility management shall be willing to perform a second decontamination either at some specified future date or based on need dictated by radiation buildup.

5. There shall be free and open cost information associated with the decontamination operations so that a complete and realistic cost benefit analysis can be performed.

6. There shall be no significant history of fuel failures, steam generator tube failures or large-diameter-pipe cracking.

7. The plant and utility management shall commit to an expanded shut down radiation measurement program that will be performed before and after the decontamination.

8. The decontamination shall be performed with the fuel in place.

9. All warranties for fuel, equipment and systems shall be the sole responsibility of the utility and no current, contingent or residual liability shall be assigned to the DOE or their contractors. 


\section{A.2 RECOMMENDED PROCESS SELECTION PREREQUISITES}

1. A dilute decontamination solution contains less than one percent chemicals by weight.

2. The demonstrated corrosion characteristics of the solution will allow completion of the decontamination with a corrosion loss of less than $10 \%$ of the allowance for the fuel, materials and systems that are in contact with the solution.

3. The dilute decontamination solution will be no more likely to produce catastrophic effects than normal plant operating conditions.

4. The decontamination solution will be suitable for the entire primary systems.

5. The process will be capable of being completed in 72 hours.

6. The company supplying the decontamination chemicals must be willing to disclose the entire solution formulation.

\section{A. 3 WEIGHTED REACTOR SELECTION CRITERIA}

1. The reactor shall have been operating for a reasonable and representative time (less than 5 years is 0 points.)

(15 points)

2. The utility must have an acceptable Health Physics Program--data from NRC-PNL Health Physics Appraisal Program will provide the basis for judgement. The utility must also show a willingness to correct deficiencies.

(25 points)

3. The plant will have an adequate shutdown radiation measurement program and history.

(30 points)

4. The utility will propose an experienced and dedicated team, familiar with the plant. The evaluation will also include any proposed contract personnel or AE staff.

(25 points)

5. The plant staff will have prior decontamination experience. 
6. The utility will submit a brief (not more than six pages) Operational Plan. (35 points)

7. The utility shall demonstrate a detailed knowledge of the wettedconstruction materials in the primary loop.

(35 points)

8. The utility shall submit a plan for determining the overall decontamination factor. (If included in the operational plan it should be an easily identifiable section.)

(15 points)

9. The utility shall present a discussion of the proposed staff training program.

(10 points)

10. The utility shall identify the major changes required to implement a dilute decontamination and shall provide an assessment of the degree of difficulty to make these changes.

(15 points)

11. The utility shall provide an overall cost estimate for the first dilute decontamination and a cost sharing proposal.

(30 points for cost realism)

12. The utility shall provide an overall schedule to support the cost est imate with key milestones/dec ision points identified.

(15 points)

\section{A.4 WEIGHTED PROCESS SELECTION CRITERIA}

1. If the decontamination solution is required to perform outside of the tested range, there shall be sufficient data available to make judicious extrapolations.

(25 points)

2. The target decontamination factor is $4-6$.

(25 points)

3. The utility shall propose any in-reactor corrosion verification testing that may be required during the decontamination. (15 points)

4. The vendor shall specify the waste volume and form.

(40 points)

5. The vendor shall submit a plan for managing the chemical and industrial safety and toxicity problems.

(15 points) 
6. The temperature of the decontamination operation shall be minimized. (Proposed operating temperatures above $160^{\circ} \mathrm{C}$ will receive 0 points.)

(25 points)

7. The vendor shall supply a proposed operating plan/approach, including a discussion of the interface with the reactor's operating crew.

(20 points)

8. The decontamination solution shall exhibit a wide range of stability, e.g., the temperature control requirements will be $\pm 10^{\circ} \mathrm{C}$ minimum; the solution can be left in the system, stagnant, for up to a week with no adverse effects.

(40 points) 
APPENDIX B

\section{SUMMARY OF TECHNICAL BACKGROUND INFORMATION FOR DILUTE DECONTAMINATION}

With Contributions By:
G. E. Zima
J. L. Nelson
J. R. Divine 
APPENDIX B

SUMMARY OF TECHNICAL BACKGROUND INFORMATION

FOR DILUTE DECONTAMINATION

\section{B.1 SIGNIFICANT MATERIALS AND RADIONUCLIDES}

\section{B.1.1 Factors Affecting the Formation of Crud Films}

The dissolved and particulate species carried by the primary coolant comprise the principal material source for fuel-deposited crud and the parent elements for radionuclide generation in both PWRs and BWRs. These species derive largely from the corrosion and erosion of the various structural materials contacted by the reactor coolant (Table B.1). Table B.1 also provides an indication of the surface area of the principal structural materials exposed to the reactor coolant of PWR and BWR plants using Zircaloy fuel cladding.

The corrosion and deposition behavior of these structural materials is affected by the plant operating conditions and the chemistry of the reactor coolant water. Table B.2 gives a comparison of the operating conditions for reactor coolant circuits for various water reactors. Table B. 3 gives the typical composition of structural materials contacting the primary coolant. Table B.4 presents corrosion rate and corrosion-product release data for these materials under typical reactor conditions such as in Table B.2. While the identity of the elements participating in crud formation can be predicted to some extent from the composition of the reactor coolant circuit materials, the gross composition of crud generally bears no discernable (simple) quantitative relationship to the composition of the participating materials, even taking surface area and corrosion rate into account.

Additional material sources for crud and radionuclide generation are: chemicals deliberately or accidently introduced to the reactor coolant by strategies for water chemistry control, water purification systems, and in-leakage of condenser coolant impurities (BWRs). The failure of the fuel cladding can introduce various fission products to the reactor coolant that 
TABLE B.1. Structural Materials Used in BWR and PWR Plants(a)

\begin{tabular}{|c|c|c|}
\hline Plant Type & Material & $\begin{array}{l}\text { Approx. \% of Surface Wetted } \\
\text { by Reactor Coolant }\end{array}$ \\
\hline \multirow[t]{4}{*}{ U.S. PWR } & Zircaloy -4 & 20 \\
\hline & Incone $1-600$ & 75 \\
\hline & 300 Series SS & 5 \\
\hline & Stellite type & $1^{(b)}$ \\
\hline \multirow[t]{4}{*}{ U.S. BWR } & Zircaloy & 48 \\
\hline & 300 Series SS & 44 \\
\hline & Carbon steel & 8 \\
\hline & Stellite type & $0.1^{(b)}$ \\
\hline \multirow[t]{3}{*}{ CANDU (PWR) } & Zircaloy & 13 \\
\hline & Monel (or Inconel or Incoloy & 77 \\
\hline & Carbon steel & 10 \\
\hline \multirow[t]{2}{*}{ CANDU (BWR) } & Zirconium alloys & 16 \\
\hline & Carbon steel & 84 \\
\hline
\end{tabular}

(a) Berry and Diegle (1979).

(b) Rough estimate, not included in Berry and Diegle (1979).

can be incorporated to some extent in the crud of both the in-core and ex-core surfaces. Fission products are a minor concern except in accident conditions and are not normally considered.

\section{B.1.2 Crud Deposition and Removal}

The materials for fuel-deposited crud enter the core region in dissolved and particulate form. Undissolved material may range from the sol and colloid regimes to particles larger than one micron. Forced convection brings both dissolved and particulate material with in the influence of short-range deposition forces. These forces are specific to the local micro-physicochemical environment and determine the course of the diffusion/migration of individual 
TABLE B.2. Comparison of Operating Conditions for Various Water Reactors

\begin{tabular}{|c|c|c|c|c|c|c|c|c|c|c|c|}
\hline \multirow[b]{2}{*}{ Reactor Types } & \multicolumn{11}{|c|}{ Operating Conditjons } \\
\hline & Fuel & Cladding & Moderator & $\begin{array}{l}\text { Reactor } \\
\text { Coolant } \\
\end{array}$ & $\begin{array}{l}\text { Coolant } \\
\text { Pressure } \\
\left(\text { MN-m }^{-2}\right)\end{array}$ & $\begin{array}{l}\text { Toolant } \\
\text { Temperature } \\
\left({ }^{\circ} \mathrm{C}\right)\end{array}$ & $\begin{array}{c}\mathrm{pH} \text { of } \\
\text { Reactor } \\
\text { Coolant } \\
\end{array}$ & $\begin{array}{l}\text { Alkaline } \\
\text { Dosing } \\
\text { Agent }\end{array}$ & $\begin{array}{l}\text { Coolant } \\
\text { Oxygen } \\
\text { Content }\end{array}$ & $\begin{array}{l}\text { Conductivity } \\
\left(\mu \text { mhos } \mathrm{cm}^{-1}\right)\end{array}$ & $\begin{array}{c}\text { Hydrogen } \\
\text { Dosing }\end{array}$ \\
\hline $\begin{array}{l}\text { Pressurized } \\
\text { Water Reactor }\end{array}$ & $\begin{array}{l}\text { Enriched } \\
\text { Uranium }\end{array}$ & Zircaloy-4 & $\mathrm{H}_{2} \mathrm{O}$ & $\mathrm{H}_{2} \mathrm{O}$ & $\sim 14$ & $250-325$ & $5-10.5$ & $\begin{array}{l}\text { Usually } \\
7_{\mathrm{LiOH}}\end{array}$ & $\sim 10 \mathrm{ppb}$ & $<2$ & Yes \\
\hline $\begin{array}{l}\text { Boiling Water } \\
\text { Reactor }\end{array}$ & $\begin{array}{l}\text { Enriched } \\
\text { Uranium }\end{array}$ & Zircaloy-2 & $\mathrm{H}_{2} \mathrm{O}$ & $\mathrm{H}_{2} \mathrm{O}$ & $-6-7$ & $250-325$ & 7 & -- & $\begin{array}{l}\text { Up to } \\
400 \mathrm{ppb}\end{array}$ & $<1$ & No \\
\hline $\begin{array}{l}\text { Steam Gen- } \\
\text { erating Heavy } \\
\text { Water Reactor }\end{array}$ & $\begin{array}{l}\text { Slightly } \\
\text { Enriched } \\
\text { Uranium }\end{array}$ & Zircaloy-2 & $\mathrm{D}_{2} \mathrm{O}$ & $\mathrm{H}_{2} \mathrm{O}$ & $\sim 6-7$ & $250-325$ & 7 & -- & $\sim 100 \mathrm{ppb}$ & $<1$ & No \\
\hline $\begin{array}{l}\text { Canadian } \\
\text { Heavy Water } \\
\text { Reactor } \\
\text { (CANDU-PHWR) }\end{array}$ & $\begin{array}{l}\text { Natural } \\
\text { Uranium }\end{array}$ & Zircaloy-2 & $\mathrm{D}_{2} \mathrm{O}$ & $\mathrm{D}_{2} \mathrm{O}$ & $\sim 14$ & $250-325$ & $9.5-10.5$ & $\begin{array}{l}{ }^{7} \mathrm{LiOH} \\
\text { or } \mathrm{NH}_{4} \mathrm{OH}\end{array}$ & $\sim 10 \mathrm{ppb}$ & $<2$ & Yes \\
\hline $\begin{array}{l}\text { Canadian } \\
\text { Heavy water } \\
\text { Reactor } \\
\text { (CANDU-BLWR) }\end{array}$ & $\begin{array}{l}\text { Natural } \\
\text { Uranium }\end{array}$ & Zircaloy-2 & $\mathrm{D}_{2} \mathrm{O}$ & $\mathrm{D}_{2} \mathrm{O}$ & $\sim 6-7$ & $250-325$ & $9.5-10.5$ & $\begin{array}{l}\text { Usually } \\
\mathrm{NH}_{4} \mathrm{OH}\end{array}$ & $\sim 10 \mathrm{ppb}$ & $<2$ & No \\
\hline
\end{tabular}

(a) The temperature range in the table covers both water and steam phases.

(b) $\mathrm{pH}$ measured at $25^{\circ} \mathrm{C}$. 
TABLE B.3. Composition of Relevant Alloys(a)

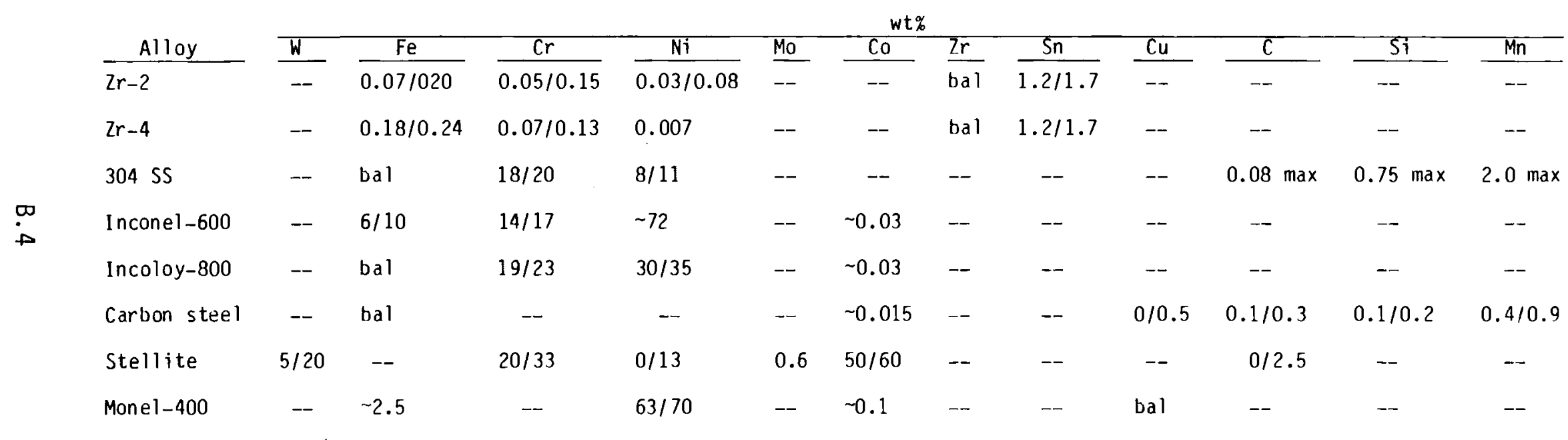

(a) Taylor (1976). 
TABLE B.4. Long-Term Corrosion and Re lease Rates of the Alloys for Nominal Conditions of Table B.2(a)

\begin{tabular}{|c|c|c|}
\hline Alloy & $\begin{array}{l}\text { Corrosion Rate, } \\
\mathrm{mg} \cdot \mathrm{dm}^{-2} \cdot \mathrm{mo}^{-1} \\
\end{array}$ & $\begin{array}{l}\text { Release Rate, } \\
\mathrm{mg} \cdot \mathrm{dm}^{-2} \cdot \mathrm{mo}^{-1}\end{array}$ \\
\hline Carbon stee 1 & $10-25$ & 10 \\
\hline Stainless steel & $2.5-5.0$ & $0.6-1.5$ \\
\hline Zircaloy $-3,-4$ & $1-8^{(b)}$ & Very low \\
\hline Mone 1-400 & 2.5 & $1.5-2.5$ \\
\hline Incone $1-600$ & $1.0-2.5$ & $1.0-1.5$ \\
\hline Incoloy -800 & $1.0-2.5$ & $1.0-1.5$ \\
\hline Steelites & $5-25$ & $5-25$ \\
\hline
\end{tabular}

\footnotetext{
(a) Taylor (1976).

(b) The highest rates occur during exposure to reactor radiation.
}

elements into the fuel-deposited crud or their rejection from the crud layer. The surface and volume energetics of the micro-environment together with the local physical conditions (temperature, heat flux, radiation field, hydrodynamics) determine the chemical state of the deposited elements and the structural characteristics of the total crud layer. The interactive effects of these factors on in-core crud structure and deposition are not we 11 characterized.

Genera11y, the PWRs appear to display some outlet (downstream of core center) peaking of the crud deposit while BWRs tend to an inlet (upstream of core center) peaking. For PWRs and BWRs there appears to be a strong inverse correlation of crud thickness with fluid shear, i.e., heavier crud deposits in both reactor types tend to occur in the peripheral core regions of relatively low flow (shear).

There is a very substantial variation in hydrodynamics, temperature, heat flux and radiation conditions with in the core. In-core crud deposits represent the effects of all of these factors, a situation that complicates the analys is of individual factors affecting in-core crud presence. 
The importance of the particulate form in the mass transfer processes involved in crud deposition has stimulated considerable analys is of the role of electrostatics in crud processes. Accordingly, work on practicable techniques for adjusting the surface charge of receptor surfaces and particles for minimizing crud depositon on critical surfaces or to effect selective adsorption/ removal of certain crud species is underway here and abroad (Tomlinson 1976; Martynova et a 1. 1977).

The $\mathrm{pH}$ of the reactor coolant water is the chemical characteristic that has received the most attention in crud control. The $\mathrm{pH}$ and temperature of the water affect the solubility of various chemical compounds involved in crud deposits. Based on the solubility data for $\mathrm{Fe}_{3} \mathrm{O}_{4}$ (a major crud compound), (Sweeton, Baes, and Jenks 1969) a high pH (greater than about 6.8 at temperature) favors dissolution of the crud in the high-temperature (core) region and deposition in the ex-core region. Conversely, a low pH favors deposition in the core region and dissolution in the ex-core region. The $\mathrm{pH}$ also affects the surface charge on particulates and thereby the course of any migration of these particulates under the influence of electric fields. Isotopic and ion-exchange processes that are believed to occur on both in- and ex-core crud deposits also may be affected by $\mathrm{pH}$.

The dissolved oxygen content of the reactor coolant water can affect both the corrosion of reactor coolant circuit materials (the crud input) and the dissolution of various species of the deposited crud. BWR plants have reported favorable effects on activity concentrations by increasing the oxygen content of the water during operation along with increases in the purification capability (Palino 1980). Oxygenation of reactor coolant, in conjunction with $\mathrm{pH}$ and temperature control, has been tested for PWR units in the course of outage work to reduce the radiation field of reactor coolant circuit equipment (Solomon and Cohen 1980).

The local hydrodynamics strongly affect crud deposition and thicknesses in the ex-core regions, particularly in respect to the particulates. The stagnant zone above the lower tube sheet of vertical PWR steam generators is a classic example of a zone favoring massive sludge buildup (in this case derived from the secondary water impurities). 
Although this document has the purpose of discussing dilute decontamination, it is worth mentioning briefly the methodology of keeping occupational exposures down by minimizing crud transport. The possibilities for exploiting the sensitivity of crud stability factors to temperature, $\mathrm{pH}$ and dissolved oxygen in effecting either temporary or permanent crud reduction on critical surfaces are encouraging. The expedient of adding ions to alter the electrochemical properties of particles and surfaces barely has been explored and shows some promise as a crud control method. The major design recourses in minimizing the impact of the crud phenomenon on radiation exposure would appear to be improving the system layout, tighter specifications on the cobalt impurity content of primary circuit structural materials, and, where practicable, substituting other metals for cobalt as a primary alloy component in wearresistant materials. An important operational recourse in minimizing the crudassociated problems of the reactor coolant system is careful maintenance of reactor coolant chemistry standards by adequate sizing and maintenance of purification units (ion-exchange beds, filters) for the coolant circuit. Such practice will contribute substantially to avoiding the extremes of coolant chemistry excursions to which the corrosion and crud-production properties of coolant circuit materials are sensitive. A constraint on manipulating the reactor coolant chemistry for the purpose of crud control is, of course, the need to minimize the corrosion effects on reactor coolant circuit components.

\section{B.2 REACTOR COOLANT SYSTEM COMPONENTS SUBJECT TO DILUTE DECONTAMINATION}

The portions of the circuit to be subjected to the dilute decontamination action will vary with the reactor type, i.e., BWR or PWR. For a given reactor type, the extent of decontamination will also be affected by the following considerations: waste volume control; the locations of the most troublesome radiation fields from the standpoint of maintenance/operation work; and the locations of components whose design and/or material composition may pose an unacceptably high risk of damage from the decontamination action, system layout, and methods available to add and remove solution. To the extent that the latter factor is nonrestrictive, the decontamination process will be controlled by the need for dose rate reduction and the reactor coolant system design limitations on circulation of the decontaminant. 
Schematics of the coolant systems of PWR and BWR reactors are shown in Figure B.1. A full-scale dilute decontamination operation could conceivably include all surfaces wetted by the reactor coolant (water/steam) of either plant type. In the case of direct-cycle BWR plants the literature generally states that the reactor coolant system would be exposed to the decontaminant, but it is mute on the extent to which parts of the coolant system subjected to steam or two-phase flow would be included in this treatment. The mechanical and material complexities of the turbine system would most certainly pose a major consideration during the predecontamination assessment of BWR decontamination.

For the BWR units, a number of decontamination circuits are conceivable because of the routing possibilities afforded by the permanent piping network of the reactor coolant system and feasible temporary modifications. At the least, an application of dilute chemical decontamination to a BWR unit would include the core recirculation loops and the clean-up loops. The incentive for including the steam-wetted portions of the BWR coolant system in the decontamination loop will depend on the factors noted earlier, which also apply to all liquid or two-phase exposed components back to the main condenser.

For the PWR unit, the potential scale of decontamination is less ambiguous. A full-circuit decontamination would probably include the following major components: the reactor core, the pressurizer, the steam generators, the coolant circulation pumps, and the primary valves. The hot- and cold-leg piping would be the principal system affected by decontamination. In addition, the various subsidiary loop systems, e.g., chemical and volume control, safety coolant injection system, residual heat removal and purification loops, could be affected depending on the temporary isolation procedures used.

\section{B.2.1 Principal Radionuclides for BWR and PWR Plants}

The spectrum of the radionuclides contributing to the radiation exposure in PWR and BWR plants varies somewhat with the plant operating time and conditions and may be perturbed by extraordinary events (e.g., fuel cladding failures) that affect the radionuclide inventory of the reactor coolant system. Table B.5 gives surface activity data for the principal radionuclides affecting 


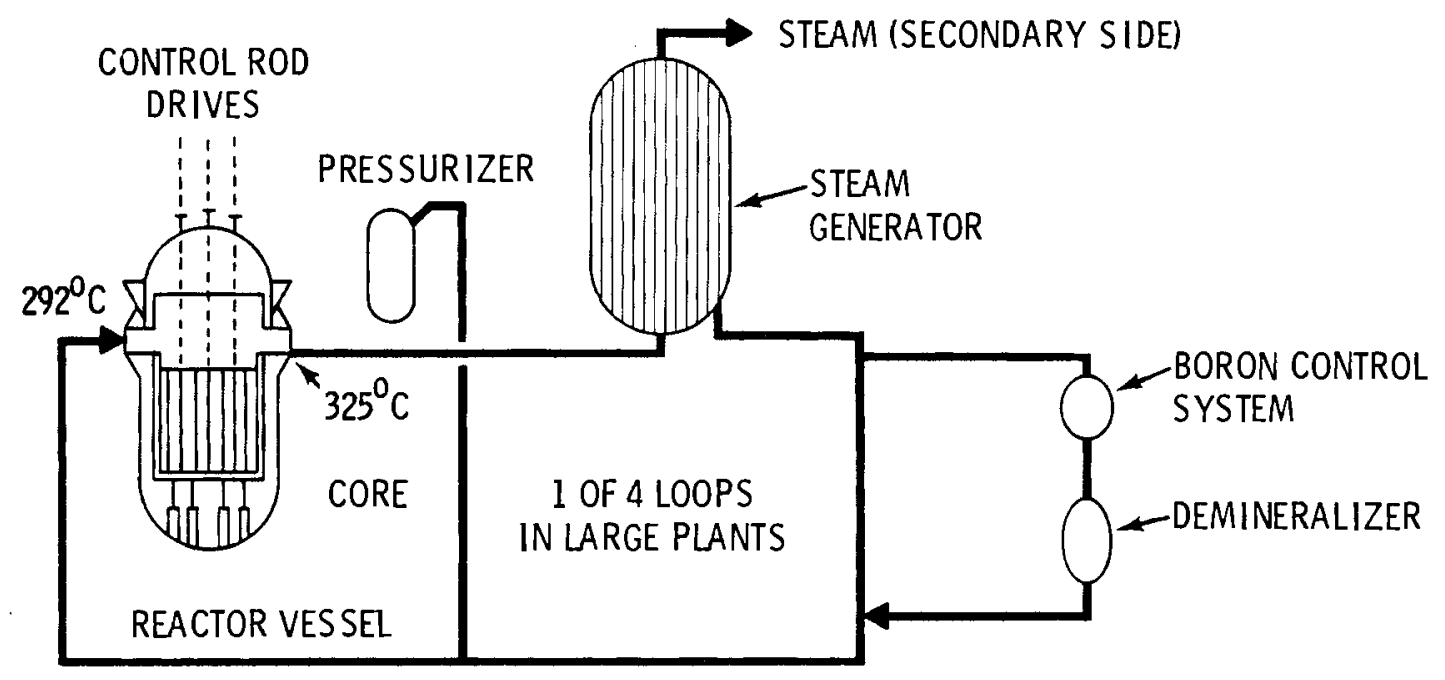

PWR

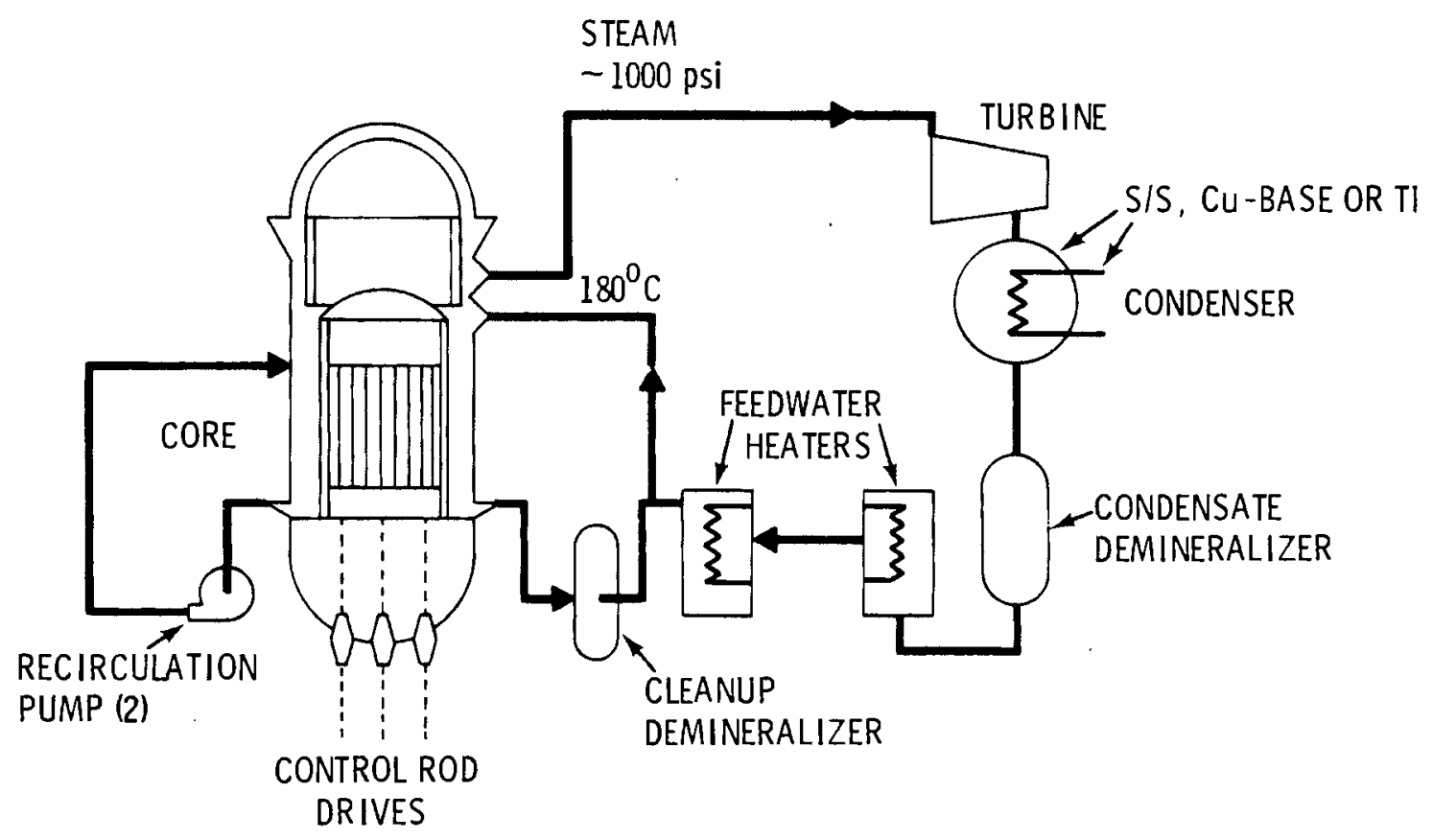

$B W R$

FIGURE B.1. Schematics of the Coolant Systems for PWR and BWR Reactors 
TABLE B.5. BWR Core and EX-Core Radionuclide Activity Densities(a)

\begin{tabular}{|c|c|c|c|c|}
\hline \multirow[b]{3}{*}{ Radionuclide } & \multicolumn{4}{|c|}{ Activity Density, $\mathrm{Ci} / \mathrm{cm}^{2}$} \\
\hline & \multicolumn{2}{|c|}{ Core ${ }^{(b)}$} & \multicolumn{2}{|c|}{ Ex-Core } \\
\hline & $\mathrm{DB}(\mathrm{C})$ & $P R^{(c)}$ & $\overline{\mathrm{DB}}$ & $P R$ \\
\hline${ }^{60} \mathrm{Co}$ & 180 & 110 & 4 & 0.7 \\
\hline${ }^{58} \mathrm{Co}$ & 50 & 40 & 2 & 0.5 \\
\hline${ }^{65} \mathrm{Zn}$ & 15 & 210 & 0.2 & 1.0 \\
\hline${ }^{59} \mathrm{Fe}$ & 80 & 15 & 0.6 & 0.2 \\
\hline${ }^{54} \mathrm{Mn}$ & 90 & 15 & 2 & 0.2 \\
\hline
\end{tabular}

(a) Berry and Diegle (1979).

(b) GE BWR after 12000 EFPH.

(c) $D B=$ deep bed demineralizer; $P R=$ powdered resin demineralizer.

the radiation exposure in BWR plants. Because these activities are affected by the type of reactor clean-up system, values are given for the two types. Table B.6 presents activity data for a typical PWR core. The absolute data in these tables will vary from reactor to reactor, but the principal radionuclides affecting the radiation exposure in these types of plants will be the same.

For BWR and PWR plants, ${ }^{60} C_{0}$ is primarily responsible for the whole body dose rate for most radiation exposure situations. This fact is supported by the following corments by Shaw, Naughton and Miller (1980).

- Cobalt-60 contributes $80 \%$ to $87 \%$ of the gamma dose rate for BWR recirculation pipes during each year of operation.

- Cobalt-58 and ${ }^{60}$ Co dominate the garma dose rate for ex-core PWR surfaces.

- Cobalt-60 becomes increasingly more important with operating time, e.g., after 3.5 effective full-power years (EFPY), the ${ }^{60}$ Co dose rate exceeds the ${ }^{58}$ Co rate by a factor of 2 to 5 .

Apart from the debris from fuel cladding failures (both fuel debris and fission products), the reactor coolant radionuclides arise from neutron 
TABLE B.6. PWR Core Radionuclide Activity Densities(a)

\begin{tabular}{cccc}
$\frac{\text { Radionuclide }}{{ }^{60} \mathrm{Co}}$ & & \multicolumn{2}{c}{ Activity Density, $\mathrm{Ci} / \mathrm{cm}^{2}$} \\
${ }^{58} \mathrm{Co}$ & & 1400 & $2-4-100$ \\
$\left.{ }^{59} \mathrm{Co}\right)$ & & \\
${ }^{5} \mathrm{Fe}$ & & 300 & $0.1-30$ \\
${ }^{54} \mathrm{Mn}$ & & 380 & \\
${ }^{51} \mathrm{Cr}$ & & 240 & $0.7-170$
\end{tabular}

(a) Zima (1978).

(b) Yankee PWR; $16,000-46,000$ MWD/MTU.

(c) Various Babcock and Wilcox plants for various operating periods.

activation of the parent elements during in-core residence. Table B.7 outlines the major neutron-activation processes.

\section{B.2.2 Crud-Film Characteristics}

The radionuclides are dispersed with in the crud films residing on the fuel elements and on the various surfaces wetted by the reactor coolant water. The chemistry and structure of these crud films are complex and may vary substantially with location within a given plant and from plant to plant of a given type depending on the design, operation, and maintenance histories of the plants. Some qualitative observations of the chemical makeup and structure of core and ex-core crud films for PWRs and BWRs are given below.

PWRS

In-Core. The structure of the in-core crud deposit varies considerably depending on the location within the core and the various plant factors (operation, maintenance and design) that affect the quantity and identity of corrosion products carried into the core by the primary water (Zima 1978). Fuel-crud deposits may be single or duplex layers. Duplex layers consist of an adherent inner layer and a loose outer layer, or single layers of various density and thickness. Ferrite and cation-substituted ferrites (e.g., $\mathrm{NiFe}_{2} \mathrm{O}_{4}, \mathrm{CoFe}_{2} \mathrm{O}_{4}$ ) appear to be the major species, mixed with $\mathrm{Cr}_{2} \mathrm{O}_{3}, \mathrm{NiO}$, and $\mathrm{Fe}_{2} \mathrm{O}_{3}$. 
TABLE B.7. Major Neutron Activation Processes

\begin{tabular}{|c|c|c|}
\hline Activation Process & Product Half-Life, d & $\begin{array}{l}\text { Saturation Activity, } \\
\mathrm{Ci} / \mathrm{mg} \text { parent }(\mathrm{a})\end{array}$ \\
\hline \multicolumn{3}{|l|}{$\begin{array}{l}\text { Thermal Neutron }(T) \\
\text { Processes: }\end{array}$} \\
\hline${ }^{50} \mathrm{Cr}(\mathrm{n}, Y){ }^{51_{\mathrm{Cr}}}$ & 28 & $2.0 \times 10^{3}$ \\
\hline${ }^{58} \mathrm{Fe}(n, \gamma){ }^{59} \mathrm{Fe}$ & 45 & $1.1 \times 10^{1}$ \\
\hline${ }^{59} \mathrm{Co}(n, \gamma){ }^{60} \mathrm{Co}$ & 1934 & $1.1 \times 10^{5}$ \\
\hline${ }^{64} \mathrm{Zn}(\mathrm{n}, \gamma){ }^{65} \mathrm{Zn}$ & 245 & $1.1 \times 10^{3}$ \\
\hline \multicolumn{3}{|l|}{$\begin{array}{l}\text { Fast neutron (F) } \\
\text { Processes: }\end{array}$} \\
\hline${ }^{58} \mathrm{Ni}(n, p){ }^{58} \mathrm{Co}$ & 72 & $1.8 \times 10^{2}$ \\
\hline${ }^{54} \mathrm{Fe}(n, p){ }^{54} \mathrm{Mn}$ & 310 & 9.0 \\
\hline
\end{tabular}

(a) Approximate saturation activity in neutron flux of $1013 \mathrm{~cm}^{-2}$ $\mathrm{sec}^{-1}$ for thermal or fast neutrons.

The chemical composition varies somewhat with the core location. Some observations of core crud structure and thickness characteristics for various PWR plants are given in Tables B.8 and B.9.

Ex-Core. There has been considerably less documentation of the ex-core crud characteristics for PWR plants than for BWRs. Crud structure and composition depend on the primary circuit location. Generally the crud is composed of $\mathrm{Ni}, \mathrm{Fe}, \mathrm{Cr}$ substituted spinels and mixed oxides (Smee 1980). A steam generator tubing film (Johnson, Griggs, and Kustas 1981) consisted of a compact inner layer of fine platelets with a sparse outer population of large superficial particles. The outer particles contained $\mathrm{Fe}, \mathrm{Cr}, \mathrm{Ni}$ and $\mathrm{Si}$ as the major species in various proportions. The inner layer also contained $\mathrm{Fe}$, $\mathrm{Cr}, \mathrm{Ni}$ and $\mathrm{Si}$ with the $\mathrm{Cr}$ in higher concentration than for the outer particles. 
TABLE B.8. Fuel-Crud Structure Observations for Various PWRs and BWRs(a)

Type/Reactor

PWR/Pt. Beach (Cycle 1)

PWR/Breznau (Cycle 1)

PWR/KWO

PWR/Yankee (Core V)

BWR/9 Mile Pt.

BWR/SGHWR

NRX \& NRU Test Loops

BWR/Various

(a) Zima (1978).
Observations

- very thin, relatively uniform layer

- individual rods exhibited various discontinuous crud patterns

- generally uniform heavy deposit, with heaviest crud in peripheral zones; black color

- crud in high heat flux zones was much thinner and gray-black, ash-white in color

- hard crud sublayer $(0.7 \mathrm{mil})$ compared to total crud thickness of $1.7 \mathrm{mil}$

- bottom several inches of rod had adherent, lustrous black crud layer

- intermediate region had thin ( 1 mil) gray layer

- top 17 in. of rods covered by loosely adherent, porous, layer of brownish-red color ( $2 \mathrm{mils}$ )

- flocculent, loosely adherent, crud layer

- no evidence of hard sublayer

- presence of Cu caused brittle, impervious, layer underneath, or sandwiched between, layers of porous iron-rich crud; cracking observed in brittle layer

- major crud layer consited of porous agglomerate of very fine iron-rich particles; the brittle crud constituent had a Cu/Fe ration of about 5.0

- in general, crud deposits were fine-grained, porous and friable of red color when neutral coolant used

- presence of $\mathrm{Cu}, \mathrm{Ni}$ and $\mathrm{Zn}$ would be expected to lead to more tenacious deposit as opposed to "reversible" iron oxides usually observed

- major constituent was reddish-brown, flocculent material; crud structure quite sensitive to water purification system

- deep-bed ion-exchanger plants tended to yield flocculent crud, easily removed by brushing

- powdered-resin plants tended to yield a relatively tenacious sublayer, under a flocculent outer layer; nonferrous elements tended to concentrate in sublayer 
TABLE B.9. Fuel-Crud Thickness Values Reported for Various PWRs and BWRs (a)

\begin{tabular}{|c|c|c|}
\hline Type/Reactor & mass/area & $\mathrm{mils}$ \\
\hline PWR/KWO & $5.0 \mathrm{mg} / \mathrm{cm}^{2}$ & 1.7 \\
\hline PWR/Pt. Beach & 0.07 to $4.6 \mathrm{~g} / \mathrm{m}^{2}$ & 0.002 to 0.15 \\
\hline PWR/Beznau & 4.7 to $47 \mathrm{~g} / \mathrm{m}^{2}$ & 0.15 to 1.5 \\
\hline PHWR/Pickering & 0.01 to $0.1 \mathrm{~g} / \mathrm{m}^{2}$ & 0.0003 to 0.003 \\
\hline PWR/Saxton & $1.0 \mathrm{~g} / \mathrm{m}^{2}$ & 0.03 \\
\hline PWR/Obrighe im & 3.0 to $80 \mathrm{~g} / \mathrm{m}^{2}$ & 0.10 to 2.7 \\
\hline PHWR/Douglas Pt. & $\begin{array}{l}2.0 \mathrm{~g} / \mathrm{m}^{2}(\text { early }) \\
0.10 \mathrm{~g} / \mathrm{m}^{2} \quad \text { (recent) }\end{array}$ & $\begin{array}{l}0.07 \\
0.003\end{array}$ \\
\hline $\begin{array}{l}\text { BWR/deep bed plant } \\
\text { powdered res in }\end{array}$ & $\begin{array}{l}4.7 \mathrm{mg} / \mathrm{cm}^{2} \\
1.4 \mathrm{mg} / \mathrm{cm}^{2}\end{array}$ & $\begin{array}{l}1.6 \\
0.5\end{array}$ \\
\hline BWR Gentilly & $8.0 \mathrm{~g} / \mathrm{m}^{2}$ & 0.3 \\
\hline BWR/Dresden & & 1.1 \\
\hline BWR/KRB. & & 4.0 \\
\hline BWR/SGHWR & & 3.0 \\
\hline BWR/SGHWR & & 5 to 6 \\
\hline
\end{tabular}

The data in Table B.9 indicate the range of fuel-crud thickness. These are thought to be representative of various stages in the plant history and various primary water chemistries and do not imply normal fuel-crud values for these plants.

BWRs

In-Core. Duplex crud layers have generally been reported, consisting of a tenacious inner layer and a loosely adherent outer layer (Anstine and Naughton 1981). Both layers consist primarily of $\mathrm{Fe}_{2} \mathrm{O}_{3}$. 
Generally, the inner layer contains much higher concentrations of nonferrous species such as $\mathrm{Co}, \mathrm{Ni}$, and $\mathrm{Cu}$ (where copper alloys are used for heat exchangers). Tables B.8 and B.9 include observations of core-crud structure and thickness characteristics for various BWR plants.

Ex-Core. Two distinct oxide layers have been observed: an inner, tightly adherent layer; and an outer, loosely-bound red oxide layer (Anstine and Naughton 1981). The inner layer consists of a porous $\mathrm{Fe}_{3} \mathrm{O}_{4}$ or mixed-cation spinel. The outer layer consists of an aggregate of $\mathrm{Fe}_{2} \mathrm{O}_{3}$ particles whose total composition is close to that measured for the water-born crud. The bulk (80\% to 90\%) of the ${ }^{60} C_{0}$ is fairly uniformly distributed through the inner layer.

\section{B.3 ESTIMATE OF TYPICAL PRIMARY SYSTEM OF CRUD AND RADIONUCLIDE INVENTORIES}

Both the crud and radionuclide inventories of the reactor coolant system vary substantially from plant to plant of a given type as a function of operating time and design. There is some indication that BWR plants produce more crud and more radionuclides; however, a detailed analys is of this complex subject is beyond the scope of this brief review. Order of magnitude estimates of the crud and radionuclide burdens of the reactor coolant systems are given in Tables B.10 to B.14, based on typical data for BWR and PWR plants. For the PWR case, the crud and radionuclide inventories are taken from a Westinghouse paper on this subject (Roesmer and Rootham 1978). This analys is is used as the basis for the order of magnitude estimation of the inventories for the BWR case using data related to crud input in BWR units from Dillon and Johnson (1976) and Uchida et al. (1980). These estimates pertain to BWR and PWR units of $1100 \mathrm{MW}(\mathrm{e})$ and $1000 \mathrm{MW}(\mathrm{e})$ capacity, respectively, and refer to one year's crudproduction after steady-state crud production conditions are reached (nominally, 2 to 12 months after startup).

In Tables B.10 to B.14 the various radionuclides do not have, necessarily, the same distribution throughout the crud. Furthermore, the distribution of radionuclides among the various components of the BWR and PWR primary circuits is poorly documented, and the observations for various types of plants have 
TABLE B.10. Crud Source Data

\begin{tabular}{|c|c|c|c|c|}
\hline Plant Type & Material & Area, $\mathrm{dm}^{2}$ & Crud Input, $\mathrm{kg}$ & Total Input, $\mathrm{kg}$ \\
\hline PWR & 304 SS & $2.2(5)^{(a)}$ & $1.9^{(b)}$ & \\
\hline$(1000 \mathrm{MW}(\mathrm{e}))$ & Inconel 600 & $1.8(6)$ & 47 & 49 \\
\hline BWR & 304 SS & $1.2(6)^{(c)}$ & $17^{(\mathrm{c})}$ & \\
\hline$(1100 \mathrm{MW}(\mathrm{e}))$ & Inconel 600 & $7.0(3)$ & 0.1 & \\
\hline & Stellite & $3.4(2)$ & 9.4 & \\
\hline & C steel & $4.0(3)$ & 135 & 160 \\
\hline
\end{tabular}

(a) $2.2(5)-2.2 \times 10^{5}$, etc.

(b) Assuming crud in form of $\mathrm{Ni}$-substituted magnetite.

(c) Estimated from data in Dillon and Johnson (1976) and Uchida et al. (1980).

TABLE B.11. Parent Element Composition of Fuel Crud

\begin{tabular}{|c|c|c|c|c|c|c|c|}
\hline & \multicolumn{7}{|c|}{ Element, wt\% } \\
\hline Plant Type & $\overline{\mathrm{Fe}}$ & $\mathrm{Ni}$ & $\mathrm{Cr}$ & $\mathrm{Mn}$ & Co & $\mathrm{Cu}$ & $\overline{Z n}$ \\
\hline$P W R^{(a)}$ & 38 & 14 & 1.5 & 0.10 & 0.03 & & \\
\hline$B W R^{(b)}$ & 80 & 4.5 & $N D^{(c)}$ & ND & 0.25 & 2.5 & 7 \\
\hline
\end{tabular}

(a) Average of data from Pt. Beach 1 and Breznau 1 cycle 1 cores (Roesmer and Rootham 1978).

(b) Average data for GE BWRs using either deep-bed or powdered-resin demineralizers; Zima (1978).

(c) $\mathrm{ND}=$ no data.

TABLE B.12. Crud Distribution

\begin{tabular}{|c|c|c|c|c|}
\hline Plant Type & Tota $1, \mathrm{~kg}$ & $\begin{array}{c}\text { Removed by } \\
\text { Purification, } \mathrm{kg}\end{array}$ & $\begin{array}{c}\text { Core } \\
\text { Inventory, } \mathrm{kg}\end{array}$ & $\begin{array}{c}\text { Ex-Core } \\
\text { Inventory, } \mathrm{kg} \\
\end{array}$ \\
\hline & 49 & 4.9 & 3.3 & 41 \\
\hline$B W R^{(a)}$ & 160 & 16 & 73 & 71 \\
\hline
\end{tabular}

(a) Assuming same purification efficiency as for PWR Units; the distribution between core and ex-core surfaces is assumed to be same as reported for Dresden-2 (Anstine 1980). 
TABLE B.13. Radionuclide Composition of Fue1 Crud

\begin{tabular}{|c|c|c|c|c|c|}
\hline & 60 & $\frac{\text { Compc }}{58}$ & ion, & $\frac{i / g}{59}$ & \\
\hline nt Typ & ${ }^{0} \mathrm{Co}$ & & & ${ }^{30 \mathrm{Fe}}$ & ${ }^{11} \mathrm{Cr}$ \\
\hline $\mathrm{NR}^{(\mathrm{a})}$ & 3 & 24 & 3 & 3.5 & 37 \\
\hline$B W R^{(b)}$ & 4.5 & 1.4 & $1.6^{\circ}$ & 1.4 & ND \\
\hline
\end{tabular}

(a) Average data from Pt. Beach 1 and Breznau 1 cycle 1 cores (Roesmer and Rootham 1978).

(b) Average data from GE BWRs using either deep-bed or powdered-res in demineralizers (Zima 1978).

TABLE B.14. A11-Location Sumary of Radionuclide Inventories of Reactor Coolant Systems

\begin{tabular}{|c|c|c|c|c|c|}
\hline Plant Type & ${ }^{60} \mathrm{Co}$ & ${ }^{58} \mathrm{Co}_{0}$ & ${ }^{54} \mathrm{Mn}$ & ${ }^{59} \mathrm{Fe}$ & ${ }^{51} \mathrm{Cr}$ \\
\hline $\operatorname{PWR}(a)$ & 220 & $\overline{2200}$ & $\overline{250}$ & 260 & 1200 \\
\hline$B W R^{(b)}$ & 4400 & 2200 & 1250 & 1400 & N \\
\hline
\end{tabular}

(a) These calculations assume that parent elements are cycled through the core in the same proportion as they appear in the fue 1 crud (Roesmer and Rootham 1978). Residence time for activation was est imated from the radionuclide activity of the core crud. Est imates ignore purification effect on inventories.

(b) BWR estimates used the same assumptions as for the PWR case. Activation was computed using the PWR data and applying a factor equal to the ratio of the BWR parent-element weight cycled through the core to that of the PWR case. 
been at wide variance. For example, references supporting over $70 \%$ retention of the radionuclides within the core are cited in Perrigo and Divine (1980). The estimates, presumably for the Dresden-2 unit for a five-year accumulation of crud, assign $90 \%$ of the total inventory of ${ }^{60}$ Co to the in-core surfaces (Anstine 1980). On the other hand, one published estimate for some CANDU units is that ex-core surfaces account for more than $90 \%$ of the ${ }^{60}$ Co (Tomlinson 1980).

The multitude of factors affecting the amount/activity and distribution of crud and radionuclides and the current limited knowledge of many of these factors and their interplay should be emphasized. Accordingly, the data in Tables B.9 through B.14 are to be regarded as no more than very rough estimates of plant crud/radionuclide inventories at a given time.

However, based on these data, it is apparent that BWRs produce more crud than PWRs and that BWR crud contains a significantly larger proportion of ${ }^{60} \mathrm{Co}$ than PWR crud. Cobalt-60 is the largest single contributor to occupational radiation exposure in either type of plant. While it appears that the greatest reduction in occupational radiation exposure would be made by decontaminating a BWR, individual differences between operating reactors may overshadow th is generalization.

\section{B.4 CRITICAL FACTORS DURING DILUTE DECONTAMINATION}

The basis for using dilute decontamination is that periodic application of mildly oxidizing or reducing solutions of dilute decontamination reagents will maintain the occupational radiation exposure associated with routing maintenance and inspections at tolerable levels. The corrosion potential of the proposed solutions for most coolant-system materials of BWR and PWR plants cannot be regarded as large considering the chemistry, the concentrations, and the short time of application of these solutions. This presumption has been supported by all of the reported corrosion tests aimed at identifying both the uniform or localized corrosion effects of dilute decontamination on reactor coolant-system materials (Tomlinson 1975; Bradbury et al. 1981) and the capacity of these dilute decontamination treatments to interfere with normal passivating characteristics under nominal operating conditions (Johnson, Griggs, 
and Kustas 1981). Some of this work (Anstine, Blomgren, and Pettit 1981; Bradbury et a1. 1981) has involved homogeneous materials as well as weld zones and dissimilar metal couplings designed to identify galvanic corrosion sensitivity to the dilute decontamination solutions. Uniform and localized corrosion tests have been conducted under both stressed and unstressed conditions. While corrosion testing of candidate dilute decontamination solutions, using structural materials specific to a given nuclear unit, will continue to be a desirable subsidiary activity of dilute decontamination programs, the present ind ications do not support any substantial concern for corrosion by current dilute decontamination solutions for proposed temperatures and times ( $f$ or ex-core components).

Corrosion effects of dilute decontamination of fuel assemblies have not been tested extensively. Considering the small size and stressed condition of many components of these assemblies, this is an area where further qualification of dilute decontamination treatments is needed for both PWR and BWR plants.

A more comprehensive view of the potential of dilute decontamination to affect the structural integrity of reactor coolant-circuit materials would include the following considerations:

- the capacity of residual chemicals of dilute decontamination to corrode the crevice zones of coolant circuit equipment, which may involve close coupling of several materials of dissimilar corrosion behavior;

- the ability of residual dilute decontamination chemicals to effect the movement of crud deposits to regions of low flow where such deposits could produce local chemical conditions favoring massive uniform or localized corrosion attack under the normal conditions. Zones of the reactor coolant system that are not readily accessible to flushing, which is done either as a part of the dilute decontamination process or in the course of normal operation following dilute decontamination, are obviously of greatest concern. Some modeling of corrosion effects of residual dilute decontamination chemicals in mechanically complex zones can and should 
be done using actual component parts insofar as is practicable. Crud-transport effects are also amenable to modeling to some extent. However, the best way to reduce concern over this aspect of dilue decontamination is to backflush the stagnant flow zones, which will minimize the residual dilute decontamination chemical content and the buildup of tramp crud. The latter action presumes an adequate capacity to remove undissolved crud dislodged by the dilute decontamination.

\section{B.5 REVIEW OF DILUTE DECONTAMINATION}

The many technical aspects of dilute decontamination and the broad scope of pertinent studies under private and agency sponsorship limit any brief state-of-the-art review to the salient findings of a few of the dilute decontamination-related programs. The reviewed work includes that of PNL, Central Electricity Generating Board organizations under EPRI sponsorship; the General Electric Co./Commonwealth Edison/DOE program; and briefly, some of the CANDECON process development.

The principal criteria for judging the success of a dilute decontamination process might be summarized as follows:

- The entry, accomplishment, and exit of the dilute decontamination activity for a given nuclear power plant should have a minimal impact on plant productivity in terms of: interruption of the power production system, critical path time assignable to the dilute decontamination, and exposure of the plant personnel to radiation and other hazards.

- The dilute decontamination should cause a reduction in the radiation exposure associated with plant maintenance/operation that is costeffective in terms of the increments gained in plant personne 1 radiation exposure and plant productivity.

Specific technical crtieria for a particular dilute decontamination process would include the following (Chopp in et al. 1979):

- The residual reagent and its decomposition products must be compatible with primary system materials both during the decontamination and the subsequent operations. 
- A dilute, mild, single solution decontamination process is desired that will achieve a decontamination factor of at least two.

- The decontamination process should operate effectively at temperatures attainable with a combination of available pump and decay heat.

- Solubilization or suspension of deposited metal oxides should be controllable so that reactor coolant purification systems can handle the cleanup.

- The decontamination process should leave the metal surfaces in a passivated or readily passivated state so that corrosion and corrosion product release rates are not accelerated on startup.

- Thermal and radiation stability of additives must be consistent with the use of dilute chemicals at the process temperature (possibly up to $200^{\circ} \mathrm{C}$ ) over two or three days of operation. Continuous makeup and feed of additional reagents is acceptable. The thermal stabilities of many ligands in aqueous solutions (e.g., EDTA, EDTP, HEDTA, DTPA) deteriorate substantially at the upper end of these temperatures.

- The process must not promote plate-out of solubilized or suspended metals and oxides over a reasonable range of $\mathrm{pH}$, oxidation potential, temperature, time, and radiation field. This criteria and the previous one should be considered together.

- Dilute decontamination capablities should include the ability to decontaminate BWRs and PWRs representing a wide range of plant design and operating/maintenance practice. The process should be costeffective in the removal of both in-core and out-of-core crud and the associated radionuclide. This implies chemical adaptability of the dilute decontamination reagents to the wide range of crud characteristics presented by current BWR and PWR plants.

Table B.15 gives a summary of reagents currently under consideration for dilute decontamination. Of these chemicals, only CAN-DECON has had exstenive application to decontamination of reactor facilities/components. This table 


\section{TABLE B.15. Reagents, Concentration and Application Temperatures Studied for Dilute Decontamination}

\begin{tabular}{|c|c|c|c|c|c|}
\hline Program & Reagent & $\begin{array}{l}\text { Concentration } \\
\text { Range }\end{array}$ & Range & $\begin{array}{l}\text { Redox Condition/ } \\
\text { Control Additives } \\
\end{array}$ & T Range, ${ }^{\circ} \mathrm{C}$ \\
\hline & BWR Orientation & & & & \\
\hline \multirow[t]{7}{*}{$\operatorname{PNL}(a, b)$} & $\begin{array}{l}\text { NTA } \\
\text { EDTA }\end{array}$ & $\begin{array}{l}0.002 M \\
0.00002-0.002 M\end{array}$ & $\begin{array}{l}5.5 \\
3.3-7.5\end{array}$ & $\begin{array}{l}\mathrm{O}_{2}(0.3 \mathrm{ppm}) \\
\mathrm{O}_{2}(0.3-43 \mathrm{ppm}) \\
\mathrm{N}_{2} \mathrm{H}_{4}\end{array}$ & $\begin{array}{l}180 \\
90-180\end{array}$ \\
\hline & HEDTA & $0.001-0.002 M$ & $3.5-5.5$ & $\begin{array}{l}\mathrm{O}_{2}(50 \mathrm{ppb}-50 \mathrm{ppm}) \\
\mathrm{N}_{2} \mathrm{H}_{4}\end{array}$ & $120-150$ \\
\hline & Oxalic Acid & $0.0005-0.002 \mathrm{M}$ & 3.5 & $\begin{array}{l}\mathrm{O}_{2}^{2}(50 \mathrm{ppb}) \\
\mathrm{N}_{2} \mathrm{H}_{4}\end{array}$ & $120-150$ \\
\hline & PWR Orientation & & & & \\
\hline & EDTA & $0.001-0.002 \mathrm{M}$ & $3.5-9.0$ & $\begin{array}{l}\mathrm{O}_{2}(0.3 \mathrm{ppm}) \\
\mathrm{N}_{2} \mathrm{H}_{4} \\
\mathrm{H}_{3} \mathrm{BO}_{3} \\
\mathrm{Fe}^{2+}(50 \mathrm{ppm}) \\
\mathrm{Cr}^{2+}(20 \mathrm{ppm})\end{array}$ & 180 \\
\hline & $\begin{array}{l}\text { NTA } \\
\text { DTPA } \\
\text { HEDTA }\end{array}$ & $\begin{array}{l}0.002 \mathrm{M} \\
0.002 \mathrm{M} \\
0.002 \mathrm{M}\end{array}$ & $\begin{array}{l}5.5 \\
5.5 \\
3.5-5.5\end{array}$ & $\begin{array}{l}\mathrm{O}_{2}(0.3 \mathrm{ppm}) \\
\mathrm{O}_{2}(0.3 \mathrm{ppm}) \\
\mathrm{O}_{2}(0.3-1.2 \mathrm{ppm}) \\
\mathrm{N}_{2} \mathrm{H}_{4}\end{array}$ & $\begin{array}{l}180 \\
180 \\
180\end{array}$ \\
\hline & $\begin{array}{l}\text { EDTA/Lactic ACid } \\
\text { DCTA/Citric ACid } \\
\text { Salacillic ACid } \\
\text { Gluconic ACid } \\
\text { Acetohydroxamic ACid } \\
\text { Dihydroxybenzoic ACid } \\
\text { Mendelic ACid }\end{array}$ & $\begin{array}{l}0.002 \mathrm{M} \\
0.002 \mathrm{M} \\
0.002 \mathrm{M} \\
0.002 \mathrm{M} \\
0.002 \mathrm{M} \\
0.002 \mathrm{M} \\
0.002 \mathrm{M}\end{array}$ & $\begin{array}{l}5.5 \\
5.5 \\
5.5 \\
5.5 \\
5.5 \\
5.5 \\
5.5\end{array}$ & $\begin{array}{l}0_{2}^{2}(0.3 \mathrm{ppm}) \\
0_{2}(0.3 \mathrm{ppm}) \\
0_{2}(0.3 \mathrm{ppm}) \\
0_{2}(0.3 \mathrm{Dpm}) \\
0_{2}(0.3 \mathrm{pDm}) \\
0_{2}(0.3 \mathrm{ppm}) \\
0_{2}(0.3 \mathrm{ppm})\end{array}$ & $\begin{array}{l}180 \\
180 \\
180 \\
180 \\
180 \\
180 \\
180\end{array}$ \\
\hline \multirow[t]{2}{*}{$G E(c, d)$} & BWR Orientation & & & & \\
\hline & $\begin{array}{l}\text { Oxalic Acid } \\
\text { Citric Acid }\end{array}$ & $\begin{array}{l}0.01 \mathrm{M} \\
0.005 \mathrm{M}\end{array}$ & 3.0 & $0_{2}(0.75 \mathrm{ppm})$ & 90 \\
\hline \multirow[t]{2}{*}{ CEGB $(e)$} & SGHWR Orientation & & & & \\
\hline & $\begin{array}{l}\mathrm{V}^{2+} \text { or } \mathrm{Cr}^{2+} \\
\text { Picolinic Acid } \\
\text { or } \\
\text { Bipyridl } \\
+ \\
\text { Formic Acid }\end{array}$ & $\begin{array}{l}0.002-0.006 \mathrm{M} \\
0.03\end{array}$ & $4.5-5.5$ & ND & 80 \\
\hline CAN-DECON $(f)$ & $\begin{array}{l}\text { CANDU Orientation } \\
\text { proprietary solution } \\
\text { [organic acid }(\sim 0.1 \text { w/o) } \\
+ \text { complexing agent + pos- } \\
\text { sibly corrosion inh ibitor; } \\
\text { oxalic and citric acids } \\
\text { have been used for solu- } \\
\text { tion makeup]. }\end{array}$ & & & & \\
\hline \multicolumn{6}{|c|}{$\begin{array}{l}\text { (a) Johnson, Griggs, and Dillon (1979). } \\
\text { (b) Fairly complete list of reagents tested } \\
\text { (c) Anstine, Blomgren, and Pettit (1981). } \\
\text { (d) Only reagents selected after screening } \\
\text { (e) Bradbury et al. (1981). } \\
\text { (f) Smee }(1980) \text {. }\end{array}$} \\
\hline
\end{tabular}


also gives an indication of the concentration range of the reagents and the temperatures used in the evaluation of the reagents in laboratory or plant decontamination work.

Table B.16 gives a sumary of laboratory or plant decontamination experience with some of the reagents listed in Table B.15. Where decontamination factors have been reported, these data are included.

Table B.17 summarizes some of the remaining study areas for various reagents as identified by the organization noted above. The table also gives several development lines indicated by these organizations in the accessible literature through 1980.

The ability of currently identified dilute decontamination techniques to cope in a cost-effective manner with the crud films of BWR, SGHWR (BWR type) and CANOU reactors appears very promising. The in-core and ex-core crud films generated in PWR plants have thus far presented considerably greater resistance to decontamination by current dilute decontamination techniques. Even though the crud formed under reducing conditions (PWRs) must be attacked by oxidizing reagents, the guidelines are not immediately evident for developing costeffective dilute decontamination reagents for PWR plants. The structural and chemical characteristics of in-core and ex-core crud films in PWRs result from the interactions of radiation, thermal and chemical factors indigenous to the primary system of these plants. The prospects are not bright for simulating the combined effects of these factors in the laboratory. Thus it appears that specimens from the primary system of a number of PWR plants, representing as wide a spectrum as possible of plant design/operation/maintenance practice, are indispensible to the development of dilute decontamination techniques for PWR plants.

The cost-effectiveness of dilute decontamination programs presently is difficult to quantify for BWR plants. The degree of satisfaction of the principal criteria noted earlier in this section by a given diiute decontamination procedure will require a number of steps beginning in the laboratory and progressing to the plant. Each of these steps will need careful planning and analysis of the results. On an industry-wide basis, cost-effectiveness can 


\section{TABLE B.16. Experience with Various Dilute Decontamination Techniques}

$\frac{\text { Program/Technique }}{(a)}$
$\frac{P N L}{\text { HEDTA }(0.001 M)}$
++
Oxalic ACid $(0.0005 \mathrm{M})$
+
Citric ACid $(0.0005 \mathrm{M})$
pH 3.6
$180^{\circ} \mathrm{C}$

EDTA (0.002M)

$\mathrm{pH} 5.5$ and 3.5

$180^{\circ} \mathrm{C}$

\begin{tabular}{l} 
Specimen/System \\
\hline BWR Orientation \\
Sections of $10-\mathrm{cm} 304$ SS pipe \\
from recirculation by-pass \\
loops of Vermont Yankee, \\
Millstone and Quad Cities \\
BWR; tested in the laboratory \\
\end{tabular}

PWR Orientation

Sections of 1-600 SG tubing from West inghouse PWRs(2), tested in the laboratory
The activity removal rates for ${ }^{60} \mathrm{Co}$ were roughly two orders of magnitude lower than rates for BWR Specimens using cited reagent for PWR work; rates were averaged over first $20 \mathrm{~min}$ of decontamination

Decontamination trends identified:

- decon up with pH decrease

- decon up with $\mathrm{H}_{2} \mathrm{O}_{2}$ addition

- decon up with additions of $\mathrm{Fe}^{2+}$ and $\mathrm{Cr}^{2+}$, with much greater effect for $\mathrm{Cr}$ ions

BWR Orientation

\begin{tabular}{|c|c|}
\hline GE & \\
\hline $\begin{array}{l}\text { Oxalic } \\
\text { Citric } \\
\mathrm{pH}^{3} \\
0.75 \\
90^{\circ} \mathrm{C}\end{array}$ & $\begin{array}{l}\text { Acid }(0.01 \mathrm{M}) \\
+ \\
\text { Acid }(0.005 \mathrm{M}) \\
\mathrm{ppm} \mathrm{O}_{2}\end{array}$ \\
\hline CEGB & \\
\hline $\begin{array}{l}v^{2+}(0 . \\
\text { Picolin } \\
\text { Formic } \\
\mathrm{pH} 4 . \\
80^{\circ} \mathrm{C} \\
60_{\mathrm{Co} \mathrm{af}}\end{array}$ & $\begin{array}{l}.002-0.006 \mathrm{M}) \\
+ \\
\text { ic Acid }(0.03 \mathrm{M}) \\
+ \\
\text { Acid } \\
5-5.5 \\
\text { fter } 11 \mathrm{hr}\end{array}$ \\
\hline
\end{tabular}

Sections of $15-\mathrm{cm} 30455$ pipe from cleanup system of

$85 \%$ of ${ }^{60} \mathrm{Co}$ removed within $15 \mathrm{hr}$

9-Mile Pt. BWR; 5-yr-old crud

Scrapings from fuel cluster of

$50-70 \%$ dissolution of crud in $12 \mathrm{hr}$ $B W R$, laboratory tests

\section{SGHWR Orientation}

Complete fuel cluster from Winfrith SGHWR

Section of 32155 piping from SGHWR riser; laboratory

SGHWR loop; laboratory

\section{CAN-DECON}

Proprietary reagent $90^{\circ} \mathrm{C}$

NPD reactor

Douglas $\mathrm{Pt}$. reactor

Gentilly

Vermont Yankee
Completely decrudded; no anomalous corrosion effects

DF of 90 for ${ }^{60} \mathrm{Co}$ after $60 \mathrm{~min}$

Section of 32155 tubing from

Overall DF 1.4 without filter:

$230 \mathrm{Ci}$ removed; DF 1.5-6.2

DF of 20 for ${ }^{60} C_{0}$ in fuel bundle

$40 \mathrm{Ci}$ removed; overall of 3

DF's averaged 7-8
London Nuclear
Reference

Johnson, Griggs and Dilion (1979)
Anstine, Blomgren, and Pettit (1981)

Bradbury (1981)

DF of $30-35$ for

Smee (1980)

DF 2.8 with filter

Remark (1980)

Decon., Ltd.

LND-101 reagent

$0.1 \mathrm{w} / 0 \%$

$95^{\circ} \mathrm{C} / 8 \mathrm{hr}$

$120^{\circ} \mathrm{C} / 16 \mathrm{hr}$

(a) Data selected to indicate typical decontamination performance of better reagents. 


\section{TABLE B.17. Study Areas and Development Lines for Various Dilute Decontamination Techniques}

Program (Ref.) PNL (a)

GE(b)

$\operatorname{CEGB}(\mathrm{c})$

CAN-DECON $(d)$

(d)
Specific Study Areas

- More extensive analysis of power of available dilute decontamination reagents to decrud PWR specimens representing range of ex-core PWR crud types

- More comprehensive evaluation of available dilute decontamination reagents on bas is of decontamination power, corrosivity and IX compatibility (clean-up and regeneration)

- Better characterization of thermal and radiation decomposition of available BWR reagents

- Characterization of available reagents for BWR and PWR fuel-crud removal

- Better characterization of particulates generated during decontamination

- Better characterization of refilming behavior of decontaminated surfaces of various materials

- Analysis of importance of testing PWR reagents with boric acid and $\mathrm{LiOH}$

- Loop testing

- Better characterization of decontamination ability of selected reagent for BWR fuel crud

- Further testing of corrosivity of selected reagent for primary system components/equipment

- Evaluation of nonvolatile products of radiolytic decomposition of citric acid and the effect on dilute decontamination action

- Loop testing

- Evaluation of the applicability of reagent to BWR and PWR core and ex-core crud

- Further characterization of the thermal and radiolytic decomposition of reagent; under thermal decomposition the effects of the surface state of affected surfaces is of particular interest

- Loop testing

\section{General Development Lines}

- Strong incentive to work with classes of compounds already quali fied for reactor service

- Reagent development for PWR core and ex-core crud $f i l m s$

- Depending on performance of current reagent, modification of reagent for BWR and PWR decontamination service

\footnotetext{
- Deve lopment of CAN-DECON PROCESS FOR BWRS

Using a reducing type reagent, typical DFs for BWR specimens are $10-20$

- Development of CAN-DECON Process for PWRS

Using a new oxidizing reagent, DFs of 5-10 are being obtained on I-600 tubing and 10-15 on 300 series SS piping from PWR primary systems (al) development work under proprietary restrictions)
}

(a) Johnson, Griggs, and Dillon (1979).

(b) Anstine, Blomgren, and Pettit (1981).

(c) Bradbury (1981).

(d) Smee (1980). 
only be judged by an analysis that covers a number of plants representing a range of crud properties and contamination levels.

\section{B.6 WASTE INVENTORIES FROM DECONTAMINATION ACTION}

The initial volume of radioactive wastes produced in a dilute decontamination is approximately proportional to the primary-system volume of the reactor facility. The final volume of radioactive material that must be disposed of depends upon the decontamination factor desired from the dilute reagent and the concentration factor desired from the volume reduction (Manion and Laguardia 1980).

The principal methods used to concentrate decontamination solutions are: precipitation, evaporation and ion exchange (Cere and Mestre 1970). Of these, ion exchange has been chosen for the volume reduction of dilute reagents. This is motivated by the simplicity of ion-exchange systems, particularly the nonregeneration systems and their greater efficiency for dilute wastes. The most significant change in procedure from normal waste management operation where ion exchange is used is that for decontamination an increased rate of replacement or regeneration of the existing ion-exchange resin is needed. This change is caused by both the increased rate of buildup of radioactivity and the high chemical-removal rate. For example, about $7200 \mathrm{~g}$-equivalents of anions must be removed from a 100,000-gal primary system decontaminated with $0.05 \%$ oxalic acid plus $0.05 \%$ citric acid. This requires about $200 \mathrm{ft}^{3}$ or more of ionexchange resin (Perrigo et al. 1979). If, as is often the case, the exchange columns are not used to capacity, as much as twice this volume of contaminated resin may be produced. If the waste contains more radioactivity than originally expected, radiation levels could force an even earlier replacement.

Current regulations require that only solidified wastes may be buried. Wastes from the dilute processes consist mostly of spent resin and filter cartridges that may be treated with a solidification agent. The four principal agents used for solidification are: cement, urea-formaldehyde, asphalt, and plastic. Only the first two are currently licensed in the U.S. Furthermore, most operators have found that urea-formaldehyde often has residual free water, which is not acceptable. The loading factor with this process is usually 
around 0.6 (0sterhout 1979). For $200 \mathrm{ft}^{3}$ of ion-exchange resin, the solid volume produced from one dilute decontamination campaign will be approximately $700 \mathrm{ft}^{3}$ (Perrigo et al. 1979). 


\section{B.7 REFERENCES}

Anstine, L. D. 1980. Dilute Chemical Decontamination Final Report. DOE/ET/34203-43, General Electric Co., San Jose, California.

Anstine, L. D., J. C. Blomgren and P. J. Pettit. 1981. "Evaluation of a Dilute Chemical Decontamination Process for Boiling Water Reactors." In Water Chemistry of Nuclear Reactor Systems 2, p. 395. British Nuclear Energy Society, London.

Anstine, L. D., and M. K. Naughton. 1981. "Radiation Level Assessment and Control for Boiling Water Reactors." In Water Chemistry of Nuclear Reactor Systems, p. 359. British Nuclear Energy Society, London.

Berry, W. E., and R. B. Diegle. 1979. Survey of Corrosion Product Generation, Transport, and Deposition in Light Water Nuclear Reactors. EPRI-NP-522, Battelle Columbus Laboratories, Columbus, Ohio.

Bradbury, D., et al. 1981. "Low Concentration Decontamination Reagent Development for LWRS." In Decontamination and Decommissioning of Reactor Facilities, p. 403. Plenum Press, New York.

Cere, P., and E. Mestre. 1970. "Treatment and Disposal of Decontamination Wastes." In Decontamination of Nuclear Reactors and Equipment, ed. J. A. Ayres. Ronald Press, New York.

Choppin, et a1. 1979. Literature Review of Dilute Chemical Decontamination Processes for Water-Cooled Nuclear Reactors. EPRI-NP-1033, Pacific Nor thwest Laboratory, Richland, Washington.

Dillon, R. L., and A. B. Johnson, Jr. 1976. "Corrosion Product Generation in Water Reactors." In Proc. System Contamination Workshop, p. 67. Electric Power Research Institute, Palo Alto, California.

Johnson, A. B., Jr., B. Griggs and R. L. Dillon. 1979. "Candidate Reagents for Activity Reduction in BWR and PWR Primary Systems." In Decontamination and Decommissioning of Reactor Facilities, p. 65. Plenum Press, New York.

Johnson, A. B., Jr., B. Griggs and F. M. Kustas. 1981. "Nature of Deposits on BWR and PWR Primary System Surfaces--Relation to Decontamination." In Water Chemistry of Nuclear Reactor Systems 2, p. 389. British Nuclear Energy Society, London.

Manion, W. J., and T. S. Laguardia. 1980. Decormissioning Handbook. DOE/EV/10128-1, Nuclear Energy Services, Inc., Danbury, Connecticut.

Martynova, 0. I., et al. 1977. "An Investigation of the Effect of Temperature on the Electrophoretic Mobility of Particles of Corrosion Products." Tep loenergetika, 24(2):70. 
Palino, G. F. 1980. "BWR Radiation Control Through Operational Practices." In Decontamination and Decommissioning of Nuclear Facilities, p. 665. Plenum Press, New York.

Perrigo, L. D., et al. 1979. The Impact of Decontamination on LWR Radioactive Waste Treatment Systems. PNL-3297, Pacific Northwest Laboratory, Richland, Washington.

Perrigo, L. D., and J. R. Divine. 1980. Decontamination Methods. PNL-SA-7770, Rev., Pacific Northwest Laboratory, Richland, Washington.

Osterhout, M. M., ed. 1979. "Decontamination and Decommissioning of Nuclear Facilities." In Proc. of American Nuclear Society Topical Meet ing in Sun Valley, Idaho, September 16-20, 1979. Plenum Press, New York.

Remark, J.F. 1980. Plant Decontamination Methods Review. Technical Planning Study 78-816, Babcock \& Wilcox Co., Lynchburg, Virginia.

Roesmer, J., and M. W. Rootham. 1978. "Estimation of Activity Inventories in Primary Circuits of Pressurized Water Reactors." In Water Chemistry of Nuclear Reactor Systems 1, p. 187. British Nuclear Energy Society, London.

Shaw, R. A., M. D. Naughton and A. D. Miller. 1980. "Radiation Exposure, Radiation Control and Decontamination." In Decontamination and Decommissioning of Nuclear Facilities, p. 679. Plenum Press, New York.

Smee, J. L. 1980. "Dissolution Characteristics of Metal Oxides in WaterCooled Reactors." In Decontamination and Decommissioning of Nuclear Facilities. Plenum Press, New York.

Solomon, Y., and J. D. Cohen. 1980. "Radiation Control in PWR Primary Systems." In Decontamination and Decommissioning of Nuclear Facilities, p. 609. Plenum Press, New York.

Sweeton, F. H., C. F. Baes and G.H. Jenks. 1969. The Solubility of Fe304 in Dilute Acid and Base Solutions. ORNL-TM-2667, Oak Ridge National Laboratory, Oak Ridge, Tennessee.

Taylor, N. K. 1976. Review of Available Data on the Release, Transport and Deposition of Corrosion Products in PWR, BWR and SGHWR Systems. AERE-R-8164, AERE Harwe 11, Chemistry Division, Oxfordshire, England.

Tomlinson, M. 1975. The Basis of Activity Transport. AECL-5113, Atomic Energy of Canada, Ltd., Whiteshel1 Nuclear Research Establishment, Pinawa, Man itoba, Canada.

Tomlinson, M. 1976. "Transport of Corrosion Products." In High Temperature High Pressure Electrochemistry in Aqueous Solutions, p. 221. National Association of Corrosion Engineers, Houston, Texas. 
Uchida, S., et al. 1980. "Corrosion Product Release Rate from Structural Materials and its Effects on Shutdown Dose Rate in the Primary Cooling System of Light Water Reactors." In Water Chemistry of Nuclear Reactor Systems 2, p. 299. British Nuclear Energy Society, London.

Zima, G. E. 1978. Comments on Fuel Crud as a Safety and Operational Factor of Independent Spent Fuel Storage Installations. NUREG/CR-0163, Pacific Northwest Laboratory, Richland, Washington. 


\section{DISTRIBUTION}

No. of

Copies

OFFSITE

A. A. Churm

DOE Patent Division

9800 S. Cass Avenue

Argonne, IL 60439

27 DOE Technical Information Center

W. Bennett

Office of Light Water Reactors

Germantown, MD 20767

5 D. Harrison

Office of Light Water Reactors

Germantown, MD 20767 .

ONS ITE

DOE Richland Operations Office
No. of

Copies

42 Pacific Northwest Laboratory

R. P. Allen

C. J. Card

R. L. Dillon

J. R. Divine

L. G. Faust

V. F. FitzPatrick (20)

W. A. Glass

G. A. Halseth

C. R. Hann

G. R. Hoenes

A. B. Johnson

R. S. Kemper

L. F. Munson

L. D. Perrigo

R. I. Smith

G. E. Zima

Technical Information (5)

Publishing Coordination (2)

H. E. Ransom 


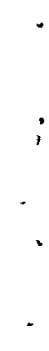

